\title{
Balance de los accidentes y desastres ocurridos en La Paz, Lima y Quito (1970-2007)
}

Bilan des accidents et catastrophes survenus à La Paz, Lima et Quito (1970-2007) Appraisal of the accidents and disasters that occurred in La Paz, Lima and Quito (1970-2007)

Robert D'Ercole, Sébastien Hardy y Jérémy Robert

\section{(2) OpenEdition} Journals

Edición electrónica

URL: http://journals.openedition.org/bifea/2233

DOI: 10.4000/bifea.2233

ISSN: 2076-5827

Editor

Institut Français d'Études Andines

Edición impresa

Fecha de publicación: 1 diciembre 2009

Paginación: 433-465

ISSN: 0303-7495

Referencia electrónica

Robert D'Ercole, Sébastien Hardy y Jérémy Robert, «Balance de los accidentes y desastres ocurridos en La Paz, Lima y Quito (1970-2007) », Bulletin de l'Institut français d'études andines [En línea], 38 (3) I 2009, Publicado el 01 junio 2010, consultado el 17 noviembre 2020. URL : http:// journals.openedition.org/bifea/2233; DOI : https://doi.org/10.4000/bifea.2233

\section{(c) (i) $\Theta$}

Les contenus du Bulletin de l'Institut français d'études andines sont mis à disposition selon les termes de la licence Creative Commons Attribution - Pas d'Utilisation Commerciale - Pas de Modification 4.0 International. 


\title{
Parte 1
}

LECCIONES DEL PASADO

1. BALANCE DE LOS ACCIDENTES Y DESASTRES

\author{
Bilan DES ACCIDENTS ET CATASTROPHES
}

APPRAISAL OF THE ACCIDENTS AND DISASTERS 



\title{
Balance de los accidentes y desastres ocurridos en La Paz, Lima y Quito (1970-2007)
}

\author{
Robert D'Ercole* \\ Sébastien Hardy* \\ Jérémy Robert***
}

\section{Resumen}

El artículo presenta un analisis de eventos, accidentes y desastres de origen natural y antrópico, que han afectado a La Paz, Lima y Quito entre 1970 y 2007. Este análisis permite conocer mejor las condiciones de vulnerabilidad de las tres capitales e intentar una comparación entre ellas. Las tres han sido frecuentemente perturbadas y dañadas sin haber conocido un evento de gran amplitud durante las últimas décadas. Sin embargo, estas ciudades presentan perfiles diferentes en lo que se refiere al origen de los eventos ocurridos. Aunque la distinción entre los factores naturales y los antrópicos sea a menudo muy difícil de realizar, es posible distinguir tendencias generales. Más bien de origen antrópico en Lima, los eventos están más ligados a factores de origen natural en La Paz, mientras que Quito presenta una situación más equilibrada. Esta distinción que las bases de datos tienden a favorecer, no esconde, sin embargo, la dificultad del estudio de eventos en un medio tan complejo como es el medio urbano. El artículo también busca reflexionar sobre las informaciones que permiten este análisis y sobre la postura tomada y las insuficiencias de las bases de datos existentes.

Palabras clave: accidentes, desastres, vulnerabilidad, bases de datos, medio urbano, La Paz, Lima, Quito

* Institut de Recherche pour le Développement (IRD), UR 029, programa Pacivur, Calle Teruel 357, Miraflores, Casilla 18-1209, Lima 18, Perú. E-mail: robert.dercole@ird.fr

** Institut de Recherche pour le Développement (IRD), UR 029, programa Pacivur, Av. Hernando Siles 5290 esq. calle 7, CP 9214 Obrajes, La Paz, Bolivia. E-mail: sebastien.hardy@ird.fr

*** Institut Français d'Études Andines (IFEA, UMIFRE 17, CNRS-MAEE)-Université de Savoie, CISM, Laboratorio EDYTEM (CNRS). E-mail: Jeremy.Robert@univ-savoie.fr 


\title{
Bilan des accidents et catastrophes survenus à La Paz, Lima et Quito (1970-2007)
}

\section{Résumé}

L'article présente une analyse événementielle des accidents et catastrophes d'origine naturelle et anthropique ayant affecté La Paz, Lima et Quito de 1970 à 2007. Cette analyse permet de mieux connaître les conditions de vulnérabilité des trois capitales et de tenter une comparaison entre elles. Toutes trois ont souvent été perturbées et endommagées sans avoir connu un évènement de grande ampleur durant les dernières décennies. Elles présentent cependant des profils différents en ce qui concerne l'origine des évènements survenus. Bien que la distinction entre les facteurs naturels et les facteurs anthropiques soit souvent très difficile à réaliser, il est possible de distinguer des tendances générales. Plutôt d'origine anthropique à Lima, les évènements sont davantage liés à des facteurs d'origine naturelle à La Paz, alors que Quito présente une situation plus équilibrée. Ce clivage que les bases de données tendent à mettre en valeur ne masque cependant pas la difficulté de l'étude évènementielle dans un milieu aussi complexe que le milieu urbain. L'article amène donc également à réfléchir sur les informations permettant cette analyse et sur le parti pris et les insuffisances des bases de données existantes.

Mots clés : accidents, catastrophes, vulnérabilité, bases de données, milieu urbain, La Paz, Lima, Quito

\section{Appraisal of the accidents and disasters that occurred in La Paz, Lima and Quito (1970-2007)}

\begin{abstract}
The paper presents an analysis of the events (accidents and disasters of natural and anthropomorphic origin) that affected La Paz, Lima and Quito from 1970 to 2007. This analysis explores conditions of vulnerability and compares the three capitals. Even if they have not been destroyed in the last decades by a calamitous event, all three have been disturbed and very often damaged. However, they have different profiles in relation to the origin of the events that occurred. Although the distinction between how natural and anthropomorphic factors share responsibility in the damage to the capital, it is difficult to establish a general trend. In Lima, the events are more related to anthropomorphic factor, while in La Paz they are more of natural origin. Quito presents more balanced situation.

The way that the databases are built tends to favour this outcome. However they also show the difficulty analyzing these events in the highly complex urban milieu. Therefore, the article asks us to think about the limitations in the information that permits this analysis and about the bias and the insufficiencies of the existing databases.
\end{abstract}

Keywords: accident, disaster, vulnerability, databases, urban environment, La Paz, Lima, Quito 


\section{INTRODUCCIÓN}

A lo largo de su historia, las capitales del Perú, de Bolivia1 y del Ecuador han sido regularmente afectadas por fenómenos de origen natural como sismos o erupciones volcánicas, y otros de origen antrópico, como incendios domésticos o contaminaciones, o mixtos en numerosos casos. En efecto, a menudo es difícil separar los factores naturales y los factores antrópicos que han originado el daño (Pigeon, 2005), por ejemplo en el caso de deslizamientos de tierra o de inundaciones. Se trata, en su conjunto, de eventos relativamente menores, por lo menos en número de muertos, como aquellos que están asociados a la mayoría de los deslizamientos de tierra registrados en La Paz o a las frecuentes inundaciones urbanas de Quito. Dentro de este conjunto resaltan episodios mayores, raros pero violentos, como el sismo y el tsunami que devastaron Lima y Callao en 1746 o la erupción del Pichincha en Quito en 1660. Encontramos pues aquello que DuboisMaury y Chaline han llamado la «nebulosa de los riesgos urbanos ordinarios». Estos numerosos eventos forman la base de una pirámide dominada por los grandes desastres ampliamente mediatizados, y reúne a una multitud de accidentes y de desórdenes cotidianos (Dubois-Maury \& Chaline, 2002) cuya acumulación es sin embargo significativa en términos de daños.

Para conocer mejor las condiciones de la vulnerabilidad de estas ciudades y para abarcar la extensión de los daños, de los menores a los mayores², es esencial contar, localizar y analizar los acontecimientos o «eventos», que denominaremos accidentes y desastres. Así enunciado, el ejercicio parece lógico y fácil. En realidad, resulta muy complejo. Primero hace falta disponer de información sobre los eventos (Coleman, 2006) para después, analizarla en función de una tipología pertinente que permita alcanzar el objetivo buscado (Gundel, 2005). Ahora bien, casi siempre las fuentes de información disponibles utilizan tipologías muy diferentes, lo cual obliga al investigador a realizar un arduo trabajo antes de utilizarlas. Además, pese a que el análisis espacial de los accidentes y desastres puede desembocar en observaciones muy interesantes, por ejemplo en términos de recurrencia de daños en ciertos espacios, este sigue siendo muy difícil de llevar a cabo. En efecto, la información almacenada en las diferentes bases de datos ha sido recolectada pocas veces con miras a ser cartografiada.

Por lo tanto, este artículo procede a un análisis de eventos proporcionando a la par una comparación entre las tres capitales y la definición de sus perfiles respectivos en materia de accidentes y de desastres registrados (tipo, frecuencia, etc.).

1 En Bolivia, la capital constitucional es Sucre pero dos de los tres poderes están instalados en La Paz: el poder legislativo y el ejecutivo. Sucre solo alberga al poder judicial. Por ende, se considera La Paz como la capital del país. En este artículo, salvo precisión, el nombre La Paz reúne a las municipalidades de La Paz y de El Alto.

2 En este artículo no establecemos un umbral entre eventos de pequeño a mediano impacto que nosotros llamamos «accidentes» y eventos de gran impacto (en vidas humanas, en familias damnificadas, en destrucciones materiales, en costos, etc.) que nosotros llamamos «desastres». En efecto, los datos de que disponemos hacen difícil establecer esta distinción. 
El artículo intenta también una reflexión sobre las informaciones que permiten este ejercicio y sobre las insuficiencias actuales de las bases de datos existentes.

\section{LAS BASES DE DATOS SOBRE LOS ACCIDENTES Y DESASTRES OCURRIDOS EN LA PAZ, LIMA Y QUITO, Y SUS LIMITACIONES}

\section{1. Diversidad de las fuentes de información o el «enredado bosque» de las cifras}

El investigador dispone de tres grandes tipos de fuentes de información, a escalas diferentes, para inventariar los accidentes y desastres que han afectado a las tres aglomeraciones urbanas:

- Las bases de datos internacionales. Una de las más utilizadas es la base EM-DAT (Emergency Events Database) del CRED (Centro de Investigación sobre la Epidemiología de los Desastres, Universidad de Lovaina (Bélgica) que proporciona informaciones sobre los desastres a escala mundial desde los inicios del siglo XX. Esta base, creada en 1988, se apoya en diferentes fuentes (fuentes gubernamentales, agencias de las Naciones Unidas, ONG, compañías de seguros, institutos de investigación, prensa, etc.) y toma en cuenta los eventos de origen natural y antrópico que reúnen por lo menos una de las siguientes condiciones: 10 muertos, 100 damnificados, declaración de estado de emergencia a escala nacional y/o demanda de asistencia ante la comunidad internacional.

- Las bases de datos regionales o nacionales. A escala latinoamericana, se utiliza la base de datos puesta a disposición desde 1996 por LA RED (Red de Estudios Sociales en Prevención de Desastres en América Latina). Esta base está construida principalmente a partir de informaciones provenientes de los diarios. Se denomina «inventario histórico de desastres» y registra eventos asociados a daños más o menos importantes que han afectado a los países de la región desde 1970. La informacion que presenta es, a menudo (pero no sistemáticamente), localizable en el seno mismo de los territorios urbanos. Además de los eventos vinculados a fenómenos de origen natural, se encuentran allí incendios, accidentes sanitarios, contaminaciones y perjuicios de diversa índole. Todos estos eventos han sido calificados de desastres3 y los autores de DesInventar se niegan a establecer umbrales como lo hace el CRED para determinar lo qué es desastre y lo qué no. Por lo tanto, una pequeña contaminación que afecta solamente a un barrio puede figurar al lado de un sismo que ha afectado al conjunto de la aglomeración y ha provocado la muerte de centenas de personas ${ }^{4}$. En

3 DesInventar define los desastres como: el conjunto de efectos sobre vidas humanas, infraestructura o economía que produce un evento sobre una unidad geográfica de máxima resolución posible. Esta definición contrasta con la concepción tradicional del desastre, en la que se toman los efectos totales causados por un evento, siempre y cuando se sobrepase un umbral de efectos predefinidos (LA RED, 2004). 
coordinación con los promotores de DesInventar y con el apoyo del programa Predecan5, los sistemas nacionales de defensa civil han implementado bases de datos nacionales. Estos datos alimentan la base DesInventar desde 2007. Las fuentes de información son numerosas, ligadas a las redes de Defensa Civil: unidades locales de Defensa Civil, bomberos, policía, Cruz Roja, etc. El número de eventos registrados es, hablando en términos proporcionales, ampliamente superior a aquel que presenta el inventario histórico de desastres de DesInventar. La base de datos del Ecuador, la única disponible actualmente6, propone 1479 fichas de eventos del 5 de enero de 2007 al 16 de marzo de 2009, o sea un promedio de 56 fichas por mes, mientras que el inventario histórico de DesInventar ofrece 4513 fichas desde el 7 de enero de 1970 hasta el 29 de diciembre de 2006, o sea un promedio de 10 fichas por mes.

- Las bases de datos nacionales temáticas y las bases locales. Se trata, por ejemplo, de las bases de datos específicas manejadas por las instituciones científicas como el Instituto Geofísico de la Escuela Politécnica Nacional sobre los eventos sísmicos y volcánicos en el Ecuador. Igualmente, el Instituto Geofísico del Perú ha registrado los sismos a escala nacional. Por su lado, el Instituto San Calixto ha compilado los movimientos sísmicos en Bolivia gracias a una red de sismógrafos instalados por todo el territorio nacional. Algunas instituciones públicas especializadas, como la unidad de Seguridad Ciudadana de la Municipalidad de Quito, proporcionan datos muy numerosos y localizados. De la misma manera, los bomberos reúnen la información sobre los incendios y otros accidentes en sus jurisdicciones.

\section{2. Ventajas y límites de las bases disponibles}

Para alcanzar nuestros objetivos de análisis de los accidentes y desastres en las tres capitales e intentar una comparación, ha sido necesario escoger entre todas estas bases de datos, sabiendo que ninguna de ellas era totalmente satisfactoria. Por un lado, el aspecto cuantitativo (número de eventos) plantea problemas en sí, como lo indica el cuadro 1. Este último concierne la aglomeración de Lima/

4 Los eventos ligados a las poluciones ilustran bien este tema. En Lima, por ejemplo, se encuentran acumulaciones de basura o también esquinas de calle convertidas en letrinas (20 casos registrados), y esto dentro de la misma tipología que una marea negra, en agosto de 1984, producto de la ruptura de un oleoducto submarino de petróleo (código 840413). Otro ejemplo son las lluvias en Lima que representan eventos relativamente particulares en esta ciudad, por su rareza, así como por los daños potenciales que pueden ocasionar debido a la ausencia total de sistema de evacuación de las aguas pluviales. Aquí también se incluyen eventos muy diferentes: se observan contrastes entre eventos que sorprenden a la población, «una inusitada lluvia sorprendió a los limeños», en febrero de 2001 (código 210106), los que perturban el tránsito, a imagen de una lluvia persistente que provocó 7 accidentes viales en julio de 1992 (código 920080) y finalmente lluvias extraordinarias como las de 1970 que dañaron más de 2000 viviendas (código 700074 y 700082), marcando así la memoria de los limeños.

5 Programa europeo de prevención de desastres en la Comunidad Andina.

6 Las bases de datos de Bolivia y del Perú siguen estando en construcción y no disponibles al $31 / 03 / 2009$. 
Callao y un territorio muy pequeño dentro de la misma —la MIRR7-. El cuadro subraya la postura de las bases de datos, pues el número de eventos, según el caso, puede ser muy grande o al contrario insignificante. Al mismo tiempo este indica el carácter relativo de la importancia otorgada al evento y a sus efectos, lo que complica la tarea del investigador.

Cuadro 1 - Número de incendios registrados en Lima según la base de datos y el periodo cubierto

\begin{tabular}{|l|c|c|c|}
\hline & $\begin{array}{c}\text { Base del CRED } \\
\text { (desde inicios del } \\
\text { siglo XX) }\end{array}$ & $\begin{array}{c}\text { Base Deslnventar } \\
\text { (desde 1970) }\end{array}$ & $\begin{array}{c}\text { Base de datos de los } \\
\text { bomberos (2004-2006) }\end{array}$ \\
\hline Lima/Callao & 2 & 971 & 18000 aprox. (1) \\
\hline MIRR & 0 & 10 & 170 \\
\hline
\end{tabular}

(1) Estimación a partir de los datos provenientes del Cuerpo de Bomberos Voluntarios del Perú (www. bomberosperu.gob.pe)

Se observa la misma situación en La Paz (cuadro 2). Al comparar los datos entre las bases se obtienen diferencias bastante importantes sobre el número de eventos ocurridos.

Cuadro 2 - Número de inundaciones que han ocasionado daños en La Paz según la base de datos y el periodo cubierto

\begin{tabular}{|c|c|c|c|}
\hline Año & Base del CRED & Base Deslnventar & Base GMLP (1) \\
\hline 2000 & 0 & 0 & 75 \\
\hline 2001 & 0 & 2 & 33 \\
\hline 2002 & 1 & 0 & 216 \\
\hline 2003 & 1 & 3 & 235 \\
\hline 2004 & 0 & 6 & 170 \\
\hline
\end{tabular}

(1) Datos provenientes del Dossier Estadístico del Gobierno Municipal de La Paz (GMLP) 2000-2005

Por otro lado, la información dada por las bases de datos puede ser sensiblemente diferente para un mismo evento. En el caso del sismo de 1974 en el Perú, el CRED y el Instituto Geofísico del Perú (IGP) concuerdan sobre el número de muertos (78) en la región de Lima. Sin embargo, el IGP, basándose en las informaciones de la Defensa Civil peruana, enumera 2500 heridos y daños importantes en algunos sectores de Lima Metropolitana y en las zonas costeras de Lurín, Chilca, Mala, Imperial, Cañete, Chincha y Pisco, mientras que el CRED registra, por su parte, más de 40000 personas damnificadas en la zona de Lima, sin dar mayores precisiones sobre la localización de las zonas afectadas. Por su lado, la base de datos DesInventar enumera, solo en la capital, 23 muertos, cerca de 6000

7 Margen izquierda del río Rímac, Cercado de Lima, superficie: 4 km². 
damnificados y 260 casas destruidas. En estas condiciones resulta difícil indicar con precisión los efectos de este sismo.

\section{2. 1. La base EM-DAT del CRED: demasiado general}

Dentro del contexto de bases de datos que proporcionan informaciones muy distintas, la base del CRED presenta la ventaja de tomar en consideración a los tres países del programa de investigación, utilizando los mismos criterios para definir lo que es un desastre. Sin embargo, si bien las informaciones han mejorado en el tiempo, tanto en el plano cuantitativo como cualitativo, en particular desde 1999 gracias a una colaboración entre el CRED y USAID/OFDA8, los datos siguen siendo incompletos. Algunas decenas de eventos concernientes a las tres capitales y registrados en la base de datos DesInventar, habrían tenido que aparecer en la base de datos del CRED ya que estos eventos respondían a los criterios de la institución. Es el caso por ejemplo del deslizamiento de tierra de Llojeta (La Paz) el 15 de abril de 1986 que afectó a más de 200 familias, por ende a cerca de un millar de personas.

Además, las zonas urbanas no se distinguen claramente en esta base y los datos que esta proporciona sobre aquellas son insuficientes. Si bien en algunos casos aparecen claramente, en otros están difuminadas en un conjunto regional, lo que hace practicamente imposible su identificación y la evaluación de las consecuencias de los eventos (número de muertos, de damnificados, etc.). Por último, casi no existe información que permita identificar a los sectores de la ciudad o a los barrios afectados.

Con respecto a las tres ciudades la base de datos del CRED registra, en total, 48 eventos, de los cuales 58 \% conciernen a Lima, $25 \%$ a Quito, y tan solo $17 \%$ a La Paz (cuadro 3), porcentajes que no parecen ilógicos si nos atenemos a la población total de las tres aglomeraciones. A pesar de sus insuficiencias, la base proporciona una primera estimación comparativa de los tipos de eventos, de fuerte impacto, para las tres ciudades. Los eventos registrados son sobre todo de tipo hidromorfológico en La Paz, con por ejemplo el deslizamiento de Cotahuma que, en 1996, mató a 40 personas o las inundaciones del 19 de febrero de 2002 (76 muertos9, más de 5000 personas afectadas). En Quito y Lima los eventos son más variados, con una importancia notable de los sismos (como los de 1940, 1966 y 1974 en Lima o el de 1987 en Quito) y de fenómenos antrópicos, como por ejemplo, la catástrofe aérea de Quito en 1988 (91 muertos) o el incendio del centro comercial Mesa Redonda en Lima en 2001 (290 muertos).

8 United States Agency for International Development.- Office of U. S. Foreign Disaster Assistance.

969 según los datos del Gobierno Municipal de La Paz (GMLP). 
Cuadro 3 - Número de desastres en La Paz, Lima y Quito según la base de datos EM-DAT del CRED

\begin{tabular}{|l|c|c|c|}
\hline Tipos de eventos (1) & La Paz (2) & Lima (3) & Quito (4) \\
\hline Inundaciones & 4 & 6 & 0 \\
\hline Deslizamientos & 1 & 2 & 2 \\
\hline Sismos & 0 & 7 & 3 \\
\hline Erupciones volcánicas & 0 & 0 & 1 \\
\hline Olas de frío & 2 & 0 & 0 \\
\hline Olas de calor & 0 & 1 & 0 \\
\hline Epidemias & 1 & 2 & 0 \\
\hline Accidentes industriales & 0 & 3 & 1 \\
\hline Accidentes de transporte & 0 & 4 & 3 \\
\hline Otros accidentes urbanos & 0 & 3 & 2 \\
\hline Total & 8 & 28 & 12 \\
\hline
\end{tabular}

(1) Eventos que han generado desastres según los criterios del CRED

(2) Ningún evento inventariado en La Paz antes de 1984

(3) Ningún evento inventariado en Lima antes de 1940

(4) Ningún evento inventariado en Quito antes de 1971

\section{2. 2. Las bases locales: poco utilizables}

Al contrario, las bases de datos locales ofrecen datos numerosos (véase arriba los cuadros 1 y 2) y a veces bien documentados en lo que se refiere a las características y consecuencias de los eventos. Sin embargo, su cobertura espacial permanece muy variable, cubren periodos distintos (generalmente muy cortos debido a su carácter reciente) y no atañen sino a algunos tipos de fenómenos.

La base de datos de los bomberos de la aglomeración de La Paz presenta otras dificultades. La información se encuentra dispersa en tres bases diferentes que corresponden a las tres compañías de La Paz y El Alto y no está homogeneizada. Esta proporciona el número de intervenciones clasificadas por tipo: fuga de gas, inundación, incendio, etc. Así, los bomberos de la estación de El Alto tuvieron que enfrentar 134 casos de inundación en 2006. Pero, aunque sus intervenciones abarcaron mayormente la municipalidad de El Alto, estos bomberos también actuaron en una zona de las vertientes occidentales de La Paz. En consecuencia, a partir de las bases de los bomberos, resulta difícil localizar los eventos con precisión. Además, cuando el evento lo justifica, pueden acudir varias compañías al mismo tiempo y el accidente aparece reportado entonces en cada una de las bases. Por último, en caso de problema, pocos habitantes llaman a los bomberos en primera instancia. Prefieren a menudo utilizar el número de emergencia implementado desde hace algunos años por el Gobierno Municipal de La Paz (GMLP). A partir de estas llamadas, los encargados municipales compilan también los casos de emergencia en los que sus servicios han actuado. 
De manera general, si bien estas bases son útiles para realizar diagnósticos muy localizados y/o para cierto tipo de accidentes, estas no permiten (por lo menos no todavía) construir un balance completo para una ciudad y menos aún establecer comparaciones entre ciudades.

\section{2. 3. La base DesInventar: la mejor opción}

Entre la base del CRED que solo registra, de manera incompleta, los eventos mayores, y las bases prolijas en información pero inutilizables para fines comparativos, la base de datos DesInventar constituye una buena opción para el investigador. A partir del momento en que el usuario es consciente que esta base registra eventos de talla y de alcance muy variables, DesInventar presenta indiscutibles ventajas, pero tambien inconvenientes que es útil conocer para evitar errores en el manejo y la interpretación de los datos.Las ventajas son de tres tipos:

- DesInventar es una base de datos de alcance regional dentro de la cual los diferentes países del programa están documentados, con cierta homogeneidad, lo que autoriza comparaciones.

- El periodo cubierto (cerca de 40 años) es bastante largo como para tener un panorama significativo de los accidentes y desastres ocurridos y para apreciar evoluciones.

- La base propone una información relativamente precisa sobre los lugares damnificados; por ende es posible reconstituir una información bastante completa a escala de las ciudades aunque en algunos casos es difícil distinguir la ciudad de los cantones, provincias o departamentos epónimos o localizar los eventos al interior de la aglomeración. En Lima, está registrada la información a escala de las provincias y de los distritos, pues la aglomeración urbana está dividida entre las provincias de Lima y El Callao, divididas respectivamente en 43 y 6 distritos respectivamente. En el caso de Quito, la espacialización de la información es menos precisa. La información está dada en función de los dos cantones de la aglomeración urbana: el cantón de Quito (Distrito Metropolitano de Quito), de lejos el más grande, y el cantón de Rumiñahui. En el caso de la aglomeración de La Paz, la escala de la información proporcionada no es siempre fácil de establecer. Los eventos pueden remitir claramente a la municipalidad de La Paz o de El Alto, las dos principales ciudades que componen la aglomeración, pero no es sistemático para nada.

Los inconvenientes son igualmente de tres tipos:

- Los criterios de selección de los eventos varían según el país. A pesar de que existe cierta coordinación entre los diferentes países, particularmente en lo referente a la fuente de información utilizada (la prensa), estos criterios de selección varían de un país a otro, más específicamente en el caso de los eventos de origen antrópico. Es así como los accidentes viales han llamado la atención de los gestionarios de la base DesInventar en Quito, mucho menos en Lima y casi nada en La Paz. De la misma manera, las diversas contaminaciones son en absoluto consignadas ampliamente en Lima, mucho menos en Quito y en La Paz a pesar de que estas no están exentas de fenómenos de este tipo. 
- Se encuentran numerosas repeticiones en la base de datos, en particular en el caso de Lima/Callao. Estas repeticiones se refieren a fenómenos que afectaron a varios distritos contemporaneamente. En este caso, el registro del evento es multiplicado por el número de distritos afectados. Por ejemplo, el huayco10 del 23 de febrero de 1998 afectó a 4 distritos apareciendo entonces cuatro veces en la base de datos (códigos 980473 a 980476). En rigor, la fábrica Famesa habría explotado ocho veces en noviembre de 1980 (códigos 800407 a 800414), cuando en realidad una sola onda de choque golpeó ocho distritos diferentes. De igual manera, los olores nauseabundos debidos a la incineración de desechos propagados por fuertes vientos afectaron 18 distritos de Lima en marzo de 1998, por lo que se registraron 18 eventos (códigos 980581 a 980611). En el caso de los sismos encontramos generalmente dos tipos de repeticiones. La primera, como en los casos precedentes, se debe al hecho que los daños conciernen a varios distritos. Se cuentan entonces tantos sismos como distritos afectados. La segunda se debe a los efectos del sismo, deslizamientos de tierra, daños estructurales, o accidentes. Por lo tanto, el sismo de 1974 provocó 9 daños en edificios, un desplome, un tsunami (clasificado como «marejada»). Está registrado al mismo tiempo 6 veces como sismo en 6 distritos diferentes, es decir 17 eventos en total. Incluso se lo asocia al daño producido en un local 15 días después. En suma, se ha contado aproximadamente 300 eventos repetidos en la base de datos de Lima, lo que representa cerca del $10 \%$ del total. El problema es menos grave en Quito y en La Paz en razón de una mayor simplicidad en la division administrativa, pero algunas repeticiones también son observables, como la tempestad de granizo del 2 de febrero de 1999 señalada dos veces en La Paz, la primera vez a escala del barrio de Villa Fátima y la segunda vez en toda la capital.

- La manera con la cual la base DesInventar clasifica los eventos engendra dos tipos de confusiones que originan otros posibles errores de interpretación.

El primer tipo de confusión concierne los accidentes y desastres que, siendo de una misma naturaleza, son clasificados de manera diferente según su causa o según los daños provocados. En Lima, en algunos casos, las lluvias son consideradas como fenómenos que engendran directamente perturbaciones o daños más o menos importantes. En otros casos, estas pasan a ser «colapsos estructurales» desde el momento en el cual provocan daños a las infraestructuras. En el primer caso se privilegia la causa, en el segundo los efectos. Los daños provocados pueden ser de orden diferente, lo que puede desembocar, aquí también, en clasificaciones diferentes. Por ejemplo, en febrero de 1976 (código 760055) se deploró el ingreso de agua túrbida en las instalaciones de Sedapal11 provocado por una serie de huaycos. El evento fue entonces clasificado como «contaminación». Algunos años antes, otro huayco había provocado los mismos daños, pero el evento aparece como un «colapso estructural».

Frecuentemente, los eventos son clasificados en función de los efectos observados, como un desbordamiento del río Rímac en marzo de 1994 (código 940447) que

\footnotetext{
10 Termino utilizado en el Peru para designar un flujo de lodo y escombros. Se utiliza mas frecuentemente el termino de aluvion en Ecuador y de mazamorra en Bolivia.

11 Servicio de agua potable y alcantarillado de Lima.
} 
arrasó con los depósitos provenientes de los reservorios de PetroPerú, lo que justificó su clasificación bajo la voz de «contaminación». Esta opción es legítima, pero el problema de fondo radica en la ausencia de reglas claras en materia de clasificación En Bolivia, la ficha 1970-0032 señala como desastre una inundación ocurrida el 24 de diciembre de 1970. A la lectura de la ficha, nos enteramos que esta se desencadenó tras una tormenta de granizo cuya precipitación alcanzó $25 \mathrm{~mm}$ de altura. En este caso, para registrar el evento, la consecuencia, a saber la inundación, es la que ha sido privilegiada, y no su causa. Otros casos, por el contrario, favorecen la causa: la ficha 1971-0001 registra una tormenta de granizo que provocó el desplome de los almacenes de la empresa Hansa en El Alto. En algunos casos, el problema ligado a la confusión entre causa y efectos es resuelto de manera incongruente duplicando el evento: en marzo de 1988, una ruptura de la red de alcantarillado de Lima es clasificada al mismo tiempo como «colapso estructural» (código 880177) y como «Contaminación» (880183).

Las confusiones ligadas a la clasificación de los accidentes y desastres pueden también generar contrasentidos. Cierto número de «inundaciones» en Lima no están ligadas a fenómenos climáticos sino a rupturas de canalizaciones de la red de agua (25 casos) o de alcantarillado (7 casos) y también a desbordamientos de canales de irrigación (25 casos) en la gran mayoría debido a su obstrucción por presencia de desechos. Si el usuario no analiza detalladamente las fichas de cada evento en la base, se encuentra en la incapacidad de distinguir las inundaciones cuyo origen es natural, por lo menos parcialmente, de aquellas totalmente antrópicas. En la misma vena, la distinción entre los movimientos de masa (derrumbes) entendidos como fenómenos hidromorfológicos, y los desplomes de algunas estructuras (techos, edificios en construcción, etc.) no es clara y provoca errores de interpretación, particularmente en los análisis estadísticos. El empleo de términos inadecuados explica en parte esta situación cuando por ejemplo un desplome de techo en Lima en junio de 2004 (código 40533) es injustamente considerado como deslizamiento de tierra. De igual manera, la ruptura de una canalización ocurrida durante el desarrollo de obras de limpieza en Quito en 1982 es clasificada como «aluvión» y se registra como un evento de origen natural.

\section{3. Adaptación de DesInventar y tipología de los eventos considerados}

Más allá de una primera estimación de los eventos ocurridos en las tres capitales a partir de la base EM-DAT del CRED, las ventajas e inconvenientes de las diferentes bases de datos nos han llevado a optar por la base de datos DesInventar con el fin de realizar los análisis y comparaciones. Sin embargo, ha sido necesario proceder a un tratamiento previo de los datos en bruto de esta base, para evitar las confusiones y los errores de interpretación señalados.

Este tratamiento ha consistido primero en suprimir gran parte de las repeticiones existentes en la base, lo que permite construir estadísticas más justas. Después, se agruparon los eventos y han sido clasificados nuevamente siguiendo reglas 
más claras, para distinguir más fácilmente los eventos de origen natural de los de origen antrópico. Además, la nueva clasificación privilegia la causa de los daños (o el evento que les da origen) y no los efectos provocados. El resultado de esta clasificación aparece en el cuadro 4.

La distinción entre los eventos de origen natural y aquellos cuyo origen es antrópico sigue siendo artificial. La responsabilidad humana está siempre presente ya sea como factor en el origen del daño, o sea como factor agravante (ejemplo: la mala calidad de la construcción en el caso de un sismo). Un daño es siempre plurifactorial con una presencia más o menos importante de factores naturales y antrópicos. Por ello la distinción propuesta permite solamente distinguir los accidentes o desastres en los cuales los factores naturales han desempeñado un rol importante al inicio (por ejemplo: las fuertes precipitaciones antes de la inundación o del deslizamiento de tierra), de los accidentes y desastres en los que el rol del hombre es ampliamente dominante, y hasta exclusivo. Esta distinción facilita al mismo tiempo la comparación entre las ciudades. Esta es sobre todo posible en el caso de los eventos ligados a fenómenos de origen natural, y menos

Cuadro 4 - Clasificación de los eventos que han generado daños hecha a partir de la base DesInventar

\begin{tabular}{|c|c|c|}
\hline \multicolumn{2}{|r|}{ Eventos ligados a } & Comentarios \\
\hline \multirow{6}{*}{ 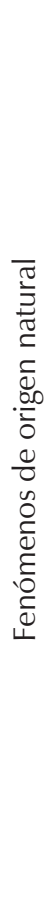 } & Fenómenos climáticos & $\begin{array}{l}\text { Incluyen heladas, neblinas, nevadas, olas de calor, } \\
\text { olas de frío, sequías, tempestades, tormentas } \\
\text { eléctricas, vendavales de la base DesInventar. } \\
\text { Incluyen también las granizadas que originan daños } \\
\text { directamente. }\end{array}$ \\
\hline & $\begin{array}{l}\text { Fenómenos hidro- } \\
\text { morfológicos }\end{array}$ & $\begin{array}{l}\text { Incluyen lluvias, inundaciones, deslizamientos, } \\
\text { avenidas torrenciales, huaycos, aluviones de la } \\
\text { base DesInventar. Se encuentran las granizadas que } \\
\text { dieron origen a inundaciones. Se han incorporado } \\
\text { algunos hundimientos clasificados «colapsos } \\
\text { estructurales»u «otros» en DesInventar. }\end{array}$ \\
\hline & Sismos & $\begin{array}{l}\text { Incluyen los sismos de la base Deslnventar a los } \\
\text { cuales se han añadido otros eventos directamente } \\
\text { vinculados con los sismos (como colapsos } \\
\text { estructurales, accidentes, deslizamientos, tsunamis, } \\
\text { etc.). }\end{array}$ \\
\hline & Erupciones volcánicas & Únicamente para Quito. \\
\hline & Marejadas & $\begin{array}{l}\text { Únicamente para Lima. Se han agrupado las } \\
\text { marejadas, oleajes y ciertas inundaciones de la base } \\
\text { DesInventar. }\end{array}$ \\
\hline & $\begin{array}{l}\text { Otros fenómenos de } \\
\text { origen natural }\end{array}$ & $\begin{array}{l}\text { Caída de árboles, daños ocasionados por animales, } \\
\text { etc. }\end{array}$ \\
\hline
\end{tabular}




\begin{tabular}{|c|c|c|}
\hline \multirow{7}{*}{ 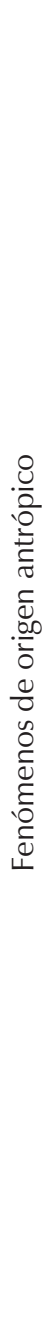 } & Contaminaciones & $\begin{array}{l}\text { Se han agrupado todas las contaminaciones, y } \\
\text { sus efectos, relacionadas con la higiene y la salud } \\
\text { humana. Incluye parte de la información de la } \\
\text { base Deslnventar denominada contaminación (de } \\
\text { todo tipo), biológico, epidemia, plaga, epizootia, } \\
\text { intoxicación. }\end{array}$ \\
\hline & Fenómenos tecnológicos & $\begin{array}{l}\text { Se han agrupado eventos que involucran actividades } \\
\text { industriales, manejo de combustibles, productos } \\
\text { químicos, etc. Se trata de incendios, explosiones, } \\
\text { accidentes, escapes de productos químicos o de } \\
\text { gases, colapsos, ciertas contaminaciones que atañen } \\
\text { a establecimientos industriales, depósitos en fábricas } \\
\text { o lugares de almacenamiento de combustibles y } \\
\text { otros productos peligrosos. }\end{array}$ \\
\hline & Accidentes de transporte & $\begin{array}{l}\text { Se distinguen claramente los accidentes ligados al } \\
\text { transporte terrestre, aéreo y marítimo (para Lima). }\end{array}$ \\
\hline & $\begin{array}{l}\text { Accidentes urbanos: } \\
\text { incendios, explosiones }\end{array}$ & $\begin{array}{l}\text { Se trata de fenómenos (incendios, explosiones) que } \\
\text { no son de tipo tecnológico sino que se relacionan } \\
\text { con actividades urbanas domésticas (accidentes } \\
\text { en la casa) o comerciales (accidentes en locales } \\
\text { comerciales o artesanales). Atañen también a los } \\
\text { edificios públicos. }\end{array}$ \\
\hline & Otros accidentes urbanos & $\begin{array}{l}\text { Se han agrupado otros tipos de accidentes urbanos, } \\
\text { más particularmente los colapsos de estructuras (de } \\
\text { todo tipo excepto los que atañen a establecimientos } \\
\text { industriales: tubería, viviendas, etc.) y las } \\
\text { inundaciones urbanas (inundaciones antrópicas). }\end{array}$ \\
\hline & Incendios forestales & Misma clasificación que en la base DesInventar. \\
\hline & $\begin{array}{l}\text { Otros fenómenos de } \\
\text { origen antrópico }\end{array}$ & $\begin{array}{l}\text { Depredación de la naturaleza (tala indiscriminada } \\
\text { de árboles, matanza de animales, etc.), deterioro } \\
\text { de zonas arqueológicas, actos de terrorismo, } \\
\text { contaminación con ruido, ahogamientos, } \\
\text { deslizamientos provocados por el hombre, etc. }\end{array}$ \\
\hline
\end{tabular}

en el caso de los eventos antrópicos porque los criterios de selección de estos eventos son muy variables según la ciudad12.

\section{ANÁLISIS DE LOS EVENTOS Y COMPARACIÓN ENTRE LAS TRES CAPITALES}

Los análisis siguientes se fundamentan en la base de datos DesInventar recompuesta tal como se ha indicado anteriormente. Estos cubren el periodo 1970-2006 en el

12 Anotemos el peso importante dado a los accidentes de transporte en Quito, mientras que están muy poco presentes en las bases DesInventar de Lima y La Paz 
caso de Lima y 1970-2007 en el caso de Quito y La Paz. Después de una primera visión de conjunto, este artículo trata de los tipos de eventos registrados en las tres aglomeraciones, de su evolución en el tiempo, de sus consecuencias y de su distribución en los territorios urbanos.

\section{1. Una visión de conjunto}

En las tres capitales se han registrado en total 3990 accidentes y desastres, o sea 108 eventos por año, 76 \% corresponden a Lima, $14 \%$ a Quito y $10 \%$ a La Paz (cuadro 5). Relacionando el número de eventos con la población actual de cada ciudad, se observa una sobrerepresentación de los eventos en Lima y una subrepresentación en La Paz y Quito. Sin embargo, la distinción de los eventos de origen natural y de los eventos de origen antrópico da otra visión de la relación eventos/población y proporciona un criterio pertinente de comparación entre las tres aglomeraciones (cuadro 5 y fig. 1).

Es evidente que Lima es afectada principalmente por accidentes y desastres de origen antrópico (82 \%) mientras que ocurre lo inverso en La Paz, en donde 78 \% de los eventos registrados son de origen natural. La Paz, con solamente el $13 \%$ de la población, reúne cerca de 28 \% de los eventos de este tipo registrados en las tres ciudades. Quito se sitúa entre las dos ciudades con un equilibrio casi perfecto entre eventos de origen natural y eventos antrópicos.

Cuadro 5 - Los accidentes y desastres de 1970 a 2007 en Lima, Quito y La Paz: algunas cifras (según la base DesInventar modificada)

\begin{tabular}{|l|c|c|c|c|c|c|c|c|}
\hline & $\begin{array}{c}\text { Número } \\
\text { eventos }\end{array}$ & $\begin{array}{c}\% \\
\text { eventos }\end{array}$ & $\begin{array}{c}\text { Número } \\
\text { eventos } \\
\text { anuales }\end{array}$ & $\begin{array}{c}\% \\
\text { población }\end{array}$ & $\begin{array}{c}\text { Número } \\
\text { eventos } \\
\text { de origen } \\
\text { natural }\end{array}$ & $\%$ & $\begin{array}{c}\text { Número } \\
\text { eventos } \\
\text { de origen } \\
\text { antrópico }\end{array}$ & $\%$ \\
\hline Lima & 3030 & 75,9 & 82 & 70,0 & 543 & 48,1 & 2487 & 86,9 \\
\hline Quito & 559 & 14,0 & 15 & 17,0 & 272 & 24,1 & 287 & 10,0 \\
\hline La Paz & 401 & 10,1 & 11 & 13,0 & 313 & 27,8 & 88 & 3,1 \\
\hline TOTAL & 3990 & 100 & 108 & 100 & 1128 & 100 & 2862 & 100 \\
\hline
\end{tabular}

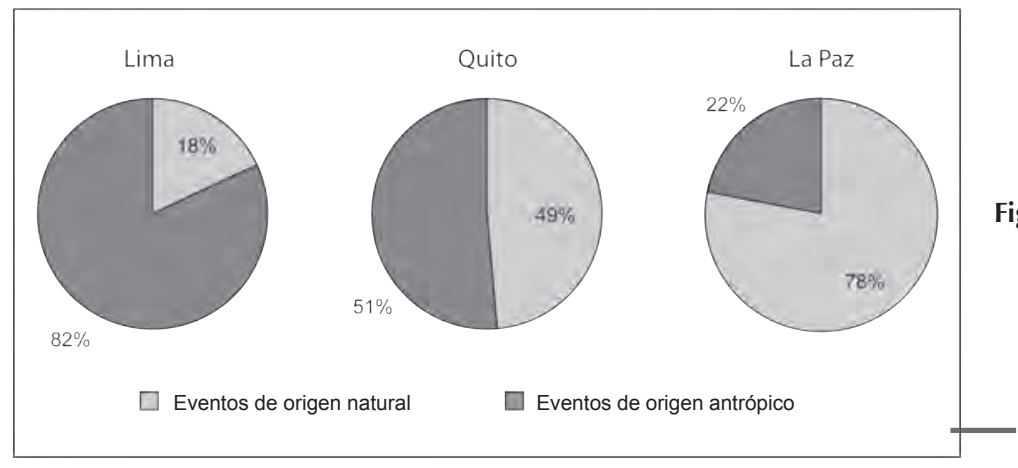

Figura 1 - Accidentes y desastres ocurridos entre 1970 y 2007 en Lima, Quito y La Paz, según su origen (según la base DesInventar modificada) 


\section{2. Tipos de eventos}

\section{2. 1. Incendios y contaminaciones en Lima, pero también fenómenos hidromorfológicos y sismos}

Los eventos más representados en Lima (cuadro 6) son los incendios (que conciernen viviendas, actividades comerciales y lugares públicos) y las contaminaciones de todo tipo, que afectan la salud de los individuos y desembocan a veces en epidemias de tifoidea o de cólera como a inicios de los años 1990.

Los incendios y las contaminaciones representan el 32,1 \% y el 25,3\%, de los eventos registrados; lo que corresponde a más de la mitad del total. En tercera posicion $(12,8 \%)$ encontramos otros accidentes urbanos que incluyen desplomes de estructuras e inundaciones urbanas ligadas al mal estado de las redes de agua potable o desagüe. Se observará igualmente la importancia de los accidentes tecnológicos relacionados principalmente con las actividades industriales. Estos eventos antrópicos, de lejos los más numerosos, no sorprenden en una aglomeración de más de 8 millones de habitantes, que ha crecido muy rápidamente y sin planificación desde la segunda mitad del siglo XX, y en la cual cerca del $40 \%$ de la población vive en situación de pobreza y de informalidad, ocupando viviendas precarias (MML, 2005). Además, en el campo industrial, la

Cuadro 6 - Tipos de eventos que han ocurrido en Lima, Quito y La Paz desde 1970 (según la base DesInventar modificada)

\begin{tabular}{|c|c|c|c|c|c|c|}
\hline \multirow[b]{2}{*}{ Eventos ligados a } & \multicolumn{2}{|c|}{ LIMA } & \multicolumn{2}{|c|}{ QUITO } & \multicolumn{2}{|c|}{ LA PAZ } \\
\hline & Número & $\%$ & Número & $\%$ & Número & $\%$ \\
\hline Fenómenos climáticos & 71 & 2,3 & 39 & 7,0 & 39 & 9,7 \\
\hline Fenómenos hidromorfológicos & 359 & 11,8 & 214 & 38,3 & 271 & 67,6 \\
\hline Sismos & 26 & 0,9 & 5 & 0,9 & 3 & 0,7 \\
\hline Erupciones volcánicas & 0 & 0,0 & 14 & 2,5 & 0 & 0,0 \\
\hline Marejadas & 77 & 2,5 & 0 & 0,0 & 0 & 0,0 \\
\hline Otros fenómenos de origen natural & 10 & 0,3 & 0 & 0,0 & 0 & 0,0 \\
\hline Contaminaciones & 766 & 25,3 & 14 & 2,5 & 11 & 2,7 \\
\hline Fenómenos tecnológicos & 239 & 7,9 & 30 & 5,4 & 7 & 1,7 \\
\hline Accidentes de transporte & 39 & 1,3 & 110 & 19,7 & 3 & 0,7 \\
\hline Incendios /Explosiones & 972 & 32,1 & 62 & 11,1 & 43 & 10,7 \\
\hline Otros accidentes urbanos & 388 & 12,8 & 12 & 2,1 & 19 & 4,7 \\
\hline Incendios forestales & 10 & 0,3 & 50 & 8,9 & 1 & 0,2 \\
\hline Otros fenómenos de origen antrópico & 73 & 2,4 & 9 & 1,6 & 4 & 1,0 \\
\hline TOTAL & 3030 & 100 & 559 & 100 & 401 & 100 \\
\hline
\end{tabular}


reglamentación, y sobre todo su aplicación, son todavía insuficientes para asegurar la seguridad mínima necesaria.

Los eventos hidromorfológicos ocupan una cuarta posición con 11,8 \%. De los 359 accidentes y desastres registrados, 170 (47 \%) están ligados a inundaciones que se registran a lo largo de los tres ríos (Chillón, Rímac y Lurín) que atraviesan el desierto costero sobre el cual está sentada la ciudad. Estas inundaciones se producen sobre todo entre diciembre y abril, correspondiendo a la estación de lluvias en la sierra13. Los otros eventos se comparten entre los flujos de lodo (huaycos), los deslizamientos de tierra que afectan más a los sectores urbanos situados al pie de los Andes u ocupando colinas, y las lluvias. Estas últimas son de escasa intensidad pero capaces de ocasionar perturbaciones o daños importantes en una ciudad que no dispone de un sistema de evacuación de las aguas pluviales. Por ello, los limeños recuerdan todavía las lluvias de enero de 197014.

Entre los otros eventos asociados a fenómenos de origen natural, figuran, en menor grado, los eventos climáticos (principalmente neblinas, vendavales), las marejadas que afectan regularmente las instalaciones costeras, y los sismos ligados a la proximidad de la zona de subducción de la placa tectónica de Nazca bajo la placa sudamericana. Estos últimos no representan ni siquiera $1 \%$ de los eventos registrados en Lima, pero no por ello dejan de ser una de las principales amenazas si nos atenemos a los daños potenciales. Según la base, 26 sismos han sacudido la capital peruana desde 1970. En ciertos casos, solamente ocasionaron espanto; en otros han habido víctimas y daños materiales importantes que deplorar como en octubre de 1974. Estos sismos pueden acompañarse de tsunamis. Ningún tsunami ha afectado la aglomeración de Lima/Callao desde 1970 pero aquel que destruyó El Callao en 1746 es recordado a menudo por los especialistas15.

\section{2. 2. Fenómenos hidromorfológicos y accidentes viales en Quito}

Los eventos asociados a fenómenos hidromorfológicos (que agrupan lluvias torrenciales, inundaciones, flujos de lodo y movimientos en masa) son, de lejos, los que más afectan a la aglomeración quiteña (38,3\%). Junto con los eventos climáticos (granizadas, vendavales), estos conforman la gran mayoría de los eventos de origen natural. Quito se sitúa en una zona de clima ecuatorial templado por la altura y combina influencias del Pacífico y de la Amazonía adulteradas por las condiciones orográficas (Sierra, 2000). El principal problema en términos de amenazas son las lluvias torrenciales, bien localizadas, de corta duración (no más de algunas horas) y a veces acompañadas de granizo, ocurren sobre todo durante los periodos que van de febrero a mayo y de octubre a noviembre. En este tipo

\footnotetext{
13 La sierra designa la parte montañosa del Perú.

14 Sumando 24 eventos registrados entre el 8 y el 19 de enero de 1970 (inundaciones, deslizamientos de tierra, corte de electricidad), las lluvias produjeron como consecuencia 1 muerto, más de 100000 damnificados, 66 viviendas destruidas y más de 2000 dañadas.

15 El sismo y el tsunami mataron a más de 3000 personas en una aglomeración que no superaba los 64000 habitantes.
} 
de condiciones se produce la mayoría de las inundaciones y de los aluviones en Quito; estos últimos afectan principalmente los flancos del volcán Pichincha. Aunque clasificadas como de origen natural, la mayoría de las inundaciones, iniciadas por fuertes precipitaciones, están ligadas ante todo a la insuficiencia de la red de evacuación de las aguas pluviales y al relleno de las quebradas16 que aseguraban la evacuación en el pasado (D’Ercole \& Metzger, 2004). En aproximadamente 50 \% del área metropolitana, las condiciones son muy propicias a la ocurrencia de amenazas geomorfológicas (Dávila, 1992): deslizamientos de tierra, derrumbes y hundimientos. Son espacios que agrupan un conjunto de características desfavorables (topografía, naturaleza de los terrenos, sistemas de drenaje, ocupación del suelo propicia a la erosión, etc.).

Los otros eventos de origen natural que afectan casualmente a la capital ecuatoriana son las erupciones volcánicas y los sismos. Quito se sitúa al pie del volcán Pichincha que erupcionó en 1999, pero la ciudad también está expuesta a otros volcanes más lejanos como el Reventador (erupción de 2002). El contexto geodinámico que origina erupciones volcánicas explica igualmente los sismos como el de 1990 y sobre todo el del 5 de marzo de marzo 1987 que, entre otros, afectó con severidad el patrimonio histórico de la ciudad.

Con respecto a los eventos asociados a fenómenos antrópicos, se observará la importancia de los accidentes de transporte que conforman un 19,7 \% del total. Este sorprendente porcentaje coloca a los accidentes de transporte, tanto terrestres como aéreos (2 eventos), en segundo lugar después de los eventos hidromorfológicos. En seguida vienen los incendios, en su mayoría domésticos $(11,1 \%)$, y los accidentes tecnológicos producto del desarrollo industrial y petrolero desde los años 1970. Una parte importante de estos accidentes está ligada a explosiones o incendios en los lugares de almacenaje de combustibles. Notemos igualmente la importancia de los incendios forestales (8,9\%) que afectan los flancos del Pichincha y varios espacios protegidos dentro del Distrito Metropolitano de Quito. Todos los incendios reportados son de origen antrópico (accidentes, vandalismo). Por su parte las contaminaciones están muy escasamente representadas (14 eventos).

\section{2. 3. Inundaciones y deslizamientos de tierra en La Paz}

En la aglomeración de La Paz, los eventos climáticos y sobre todo hidromorfológicos (77,3 \% de los accidentes y desastres) son de lejos los más frecuentes. La topografía de declives abruptos ligada a la naturaleza de las formaciones geológicas explica que las precipitaciones, a menudo violentas, favorezcan el inicio de procesos físicos que originan deslizamientos de tierra e inundaciones. La base de datos indica tres eventos sísmicos (1988, 1998 y 2001) a pesar de que la aglomeración de La Paz no se considera como una zona sísmica activa. Estos sismos, aunque alejados, generaron daños (esencialmente fisuras) por causa de la inestabilidad de los terrenos y de la mala calidad de numerosas construcciones.

16 Torrenteras que entallan los flancos del volcán. 
Los eventos de origen natural lo llevan a los acidentes antrópicos y, entre aquellos, descuellan los incendios (10,7 \%). El análisis de sus causas revela que estos se deben a cortocircuitos ligados a instalaciones eléctricas en mal estado, al mal manejo de fuegos artificiales, y a la explosión de recipientes de gas o de instalaciones de calefacción. Unos cuantos eventos tecnológicos representados (1,7%) corresponden igualmente a incendios pero que afectan a actividades industriales. Solo 11 eventos son clasificados en la categoría «contaminaciones» y se relacionan principalmente con casos de epidemia (epidemias de cólera, infecciones nosocomiales) ligadas a las condiciones sanitarias y a la existencia de focos de polución de los cuales se reportan algunos casos. En su conjunto, es sorprendente sin embargo el muy escaso número de contaminaciones, de accidentes tecnológicos o de transporte. Los eventos consignados se acercan más a aquellos observables en el medio rural que a los que caracterizan a una gran ciudad. Estas constataciones se explican fácilmente. Por causa de los declives, de la falta de espacio para instalar importantes infraestructuras viales y de la menor presencia de oxígeno, el tránsito automotor en La Paz es poco importante y lento. Además, por razones históricas, La Paz se ha desarrollado en torno a las funciones administrativas de sede del gobierno, dejando ampliamente de lado a las actividades industriales relativamente poco numerosas en el espacio urbano.

\section{2. 4. Algunas enseñanzas de la comparación entre las tres capitales}

La observación de la distribución de los tipos de accidentes y de desastres registrados desde 1970 señala puntos comunes y diferencias entre las tres ciudades además de sus especificidades. Esto se explica por las características propias de cada ciudad, resumidas más arriba, pero también por las diferentes modalidades de constitución de los datos, sobre todo cuando se tratan de fenómenos antrópicos.

La comparación más pertinente concierne a los accidentes y desastres de origen natural (fig. 2). En efecto, los criterios de selección de estos eventos parecen haber sido los mismos en todos los lugares, por ser fenómenos que en su conjunto son mejor conocidos y mejor manejados que los fenómenos de origen antrópico. La figura muestra sin ambigüedad que los eventos climáticos e hidromorfológicos son de lejos los más representados en cada una de las tres aglomeraciones, a pesar de las diferencias notables en materia de sitio urbano y de condiciones climáticas entre las ciudades. Desde este punto de vista, Quito y La Paz, ciudades de altura (2800 y 3800 m.s.n.m en promedio), se distinguen claramente de Lima, ciudad costera del Pacífico con clima desértico. Sin embargo, las inundaciones y fenómenos hidromorfológicos que afectan a la capital peruana están estrechamente ligados a la situación climática de los Andes vecinos. La figura señala otro punto en común en relación a los sismos, aun cuando estos generan muchos más problemas en Lima que en La Paz; Quito se sitúa en una posición intermedia. Por último, aparecen las especificidades: las mareas en Lima y las erupciones volcánicas en Quito.

La comparación de los accidentes y desastres de origen antrópico plantea problemas y denota la dificultad de constituir una base de datos en este campo. 


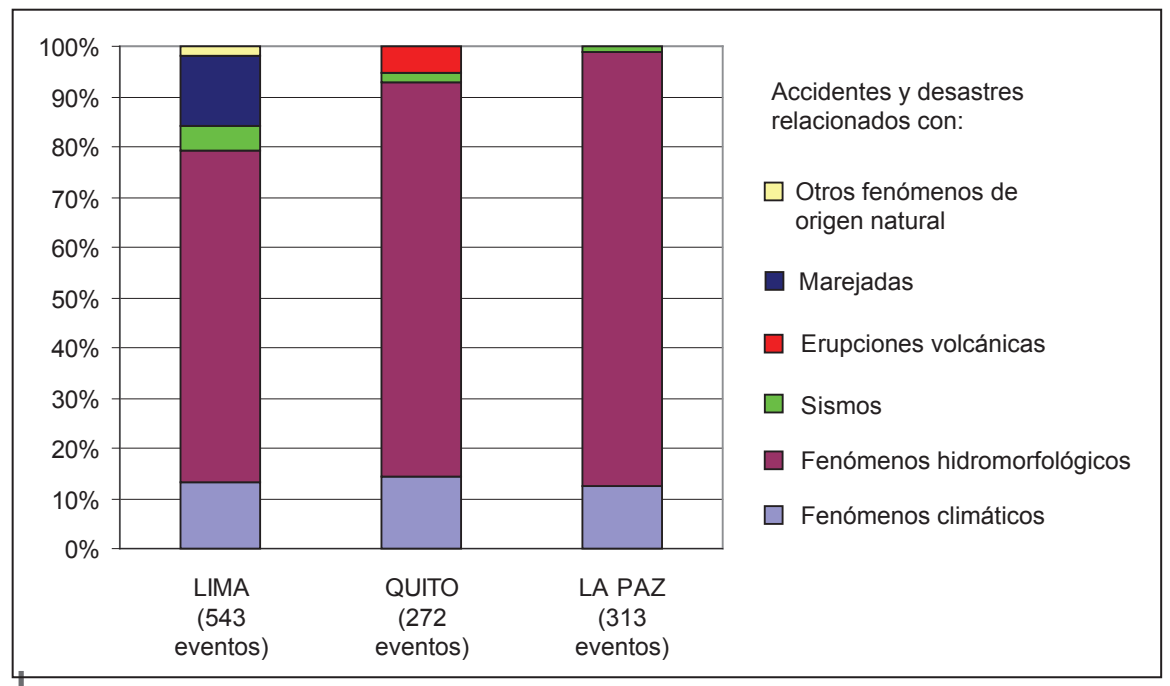

Figura 2 - Disribución por tipo de accidentes y desastres de origen natural en Lima, Quito y La Paz (1970-2007)

Además de la diferencia cuantitativa del número total de eventos entre las ciudades (28 veces más eventos en Lima que en La Paz), parcialmente justificada por la diferencia demográfica, resulta sorprendente la importancia adquirida por ciertos tipos de accidentes (fig. 3). En Lima, resaltan principalmente los incendios y las contaminaciones, en Quito, los accidentes de transporte. En La Paz, los más numerosos son los incendios pero el número de eventos es demasiado pequeño como para sacar conclusiones.

Las distorsiones observadas parecen depender de las elecciones hechas en la constitución de los datos, las cuales están ligadas en parte a la manera cómo los fenómenos son percibidos por las personas directa o indirectamente involucradas en la producción y la recolección de los datos. Esto puede parecer sorprendente en el caso de una base de datos constituida a escala regional, que normalmente dispone de criterios comunes para cada país. Pero es evidente que los accidentes de transporte han sido privilegiados en Quito mientras que han sido considerados como secundarios (o más difíciles de estimar) en La Paz y en Lima17 y esto, más aún si consideramos que el tercio de los accidentes registrados en Lima están relacionados con el transporte marítimo. Únicamente 24 accidentes terrestres han sido registrados en Lima (contra 108 en Quito) cuando la base de datos de los bomberos de Lima menciona cerca de 5000 intervenciones ligadas a accidentes viales en tan solo el año 2008.

La misma reflexión es válida para las contaminaciones. Las visitas de campo muestran que estas son numerosas tanto en Quito como en La Paz, pero se encuentran

17 En Lima más del tercio de los accidentes de este tipo están relacionados con el transporte marítimo. 


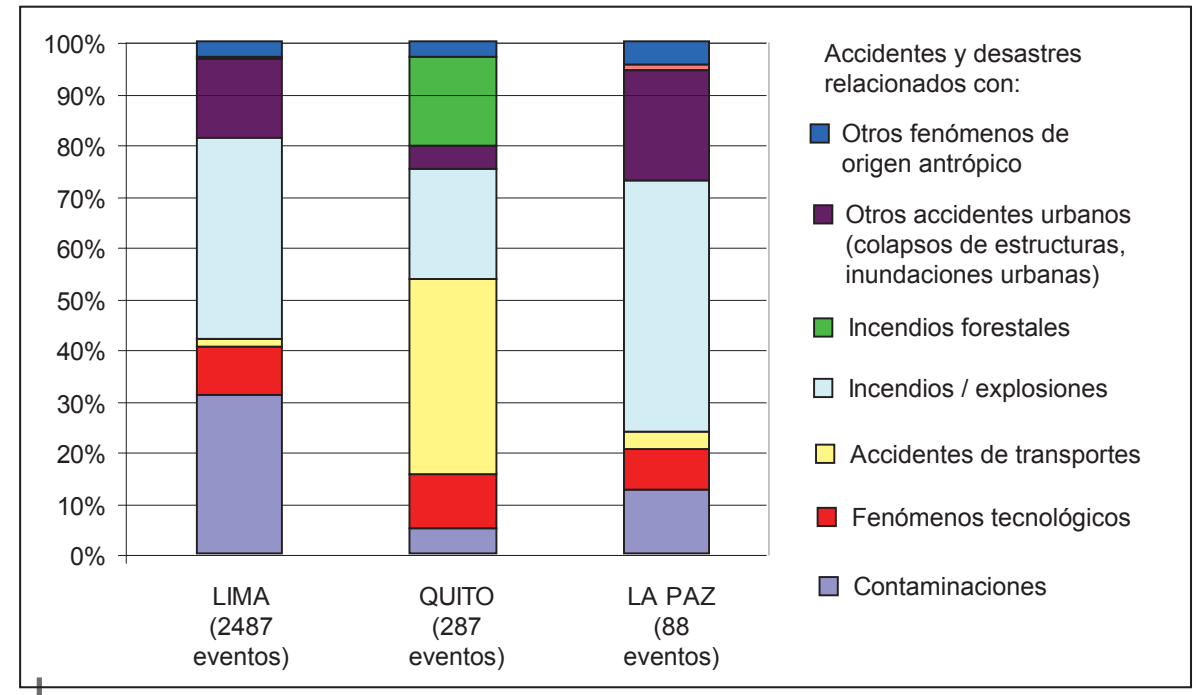

Figura 3 - Distribución por tipo de accidentes y desastres de origen antrópico en Lima, Quito y la Paz (1970-2007)

escasamente reportadas en la base. Nuestra hipótesis es que el problema está ligado, por lo menos en parte, a la calidad de la cobertura periodística del evento. En La Paz, los periódicos utilizados por DesInventar ponen más atención a lo que ocurre en la ciudad de La Paz que a lo que acontece en El Alto, mucho más industrial y en donde tienden a concentrarse las poluciones. La percepción individual de los responsables del ingreso de la información constituye con seguridad otro problema: es difícil para muchos diferenciar un evento banal de la vida cotidiana (un accidente automovilístico, la contaminación de una esquina de calle debida a alguna basura) de un evento más grave digno de figurar en una base de datos sobre accidentes y desastres. Esta distinción parece generar menos problemas en el caso de los eventos de origen natural. Se evidencia entonces la necesidad de un umbral que permita incluir un evento en la base, o al contrario, descartarlo.

\section{3. Evolución en el tiempo}

Según las figuras 4 A, B y C, salvo Lima en donde el número de eventos de origen natural parece relativamente estable y el de los eventos antrópicos en disminución desde el periodo 1985-1989, el número de eventos registrados aumenta (en Quito y La Paz la inflexión del último periodo está ligada a su corta duración: dos años en el caso de Lima, tres en los de Quito y La Paz). Sin embargo, es difícil apreciar con claridad la evolución de estos eventos en la medida en que el ingreso de la información a la base DesInventar parece no haber sido regular desde 1970, lo 


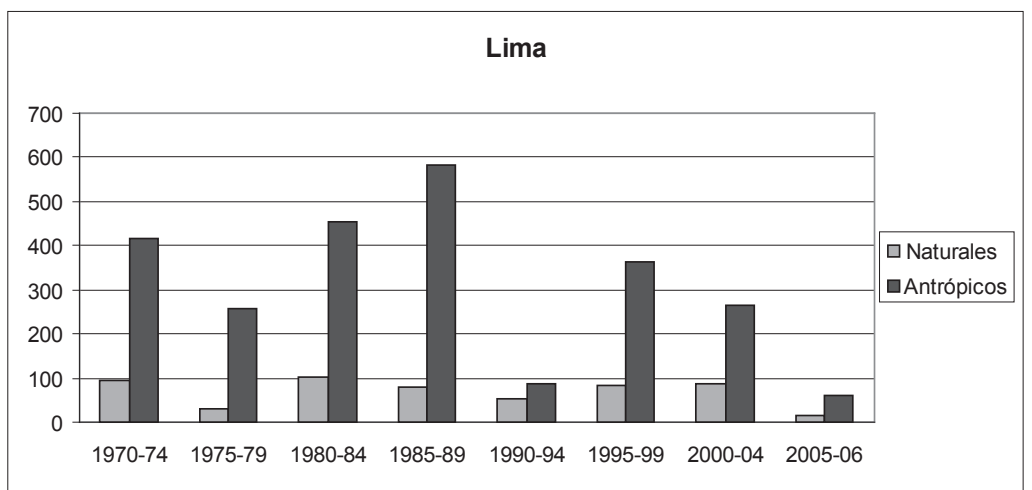

B

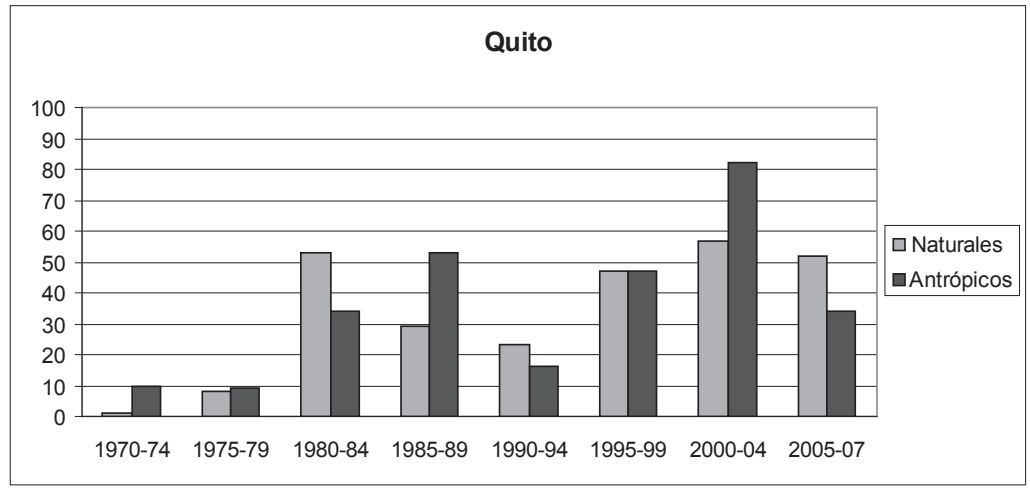

C

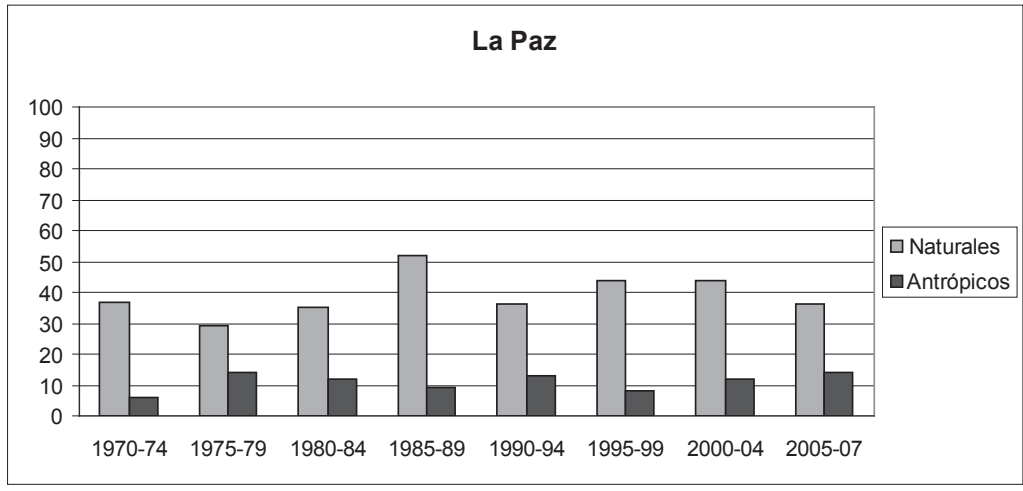

Figura 4 A, B y C - Evolución del número de accidentes y desastres ocurridos en Lima, Quito y La Paz (1970-2007) (según la base DesInventar modificada) 
que puede explicar algunos vacíos en los gráficos: por ejemplo durante el periodo 1990-1994 en Lima o los periodos 1970-1974 y 1975-1979 en Quito (muy pocos eventos registrados antes de 1980).

La figura 5, centrada únicamente en los eventos hidromorfológicos muy bien representados en cada aglomeración, permite observar ya sea un aumento o un mantenimiento de su número. Sin embargo la evolución no es regular y se observan algunos picos como los del periodo 1980-1984 en Lima y Quito, ligados en parte al fenómeno de El Niño de 1982-1983.

El número de eventos que han provocado daños no ha disminuido globalmente desde 1970, pero al parecer ha disminuido el número de eventos por habitante si consideramos el aumento de la población de las tres ciudades18. Sin embargo, es difícil pronunciarse sobre este tema con certeza en razón de las debilidades observadas en la base de datos DesInventar.

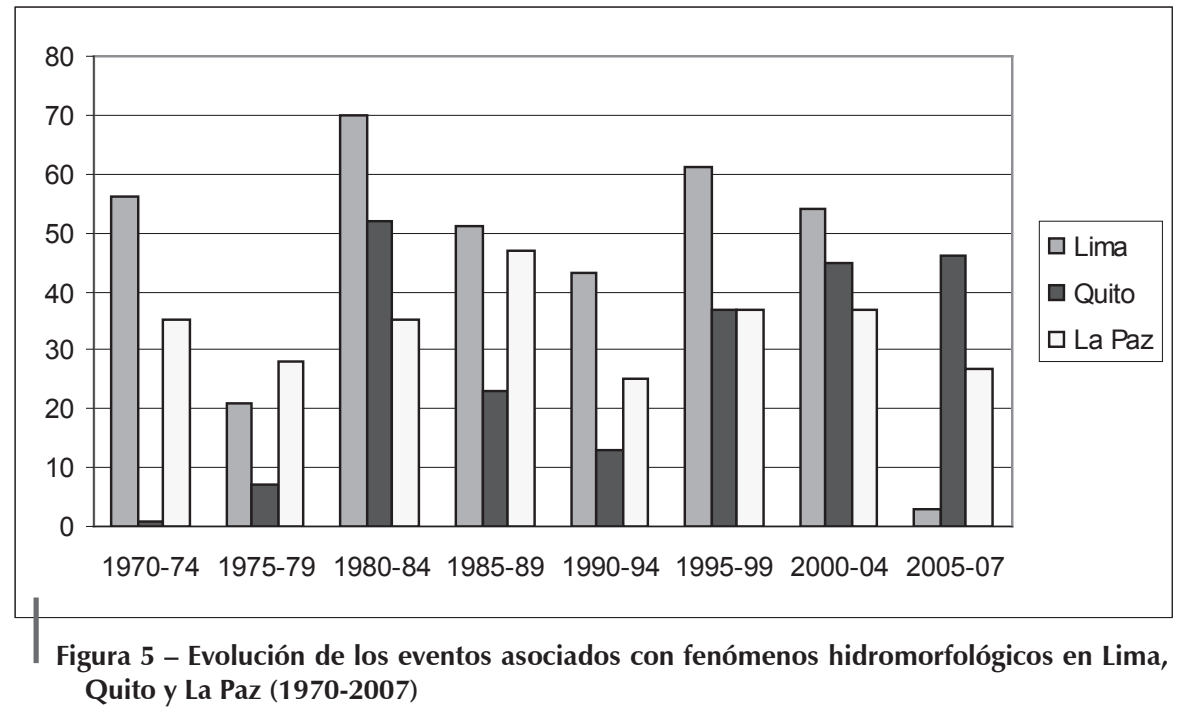

\section{4. Los daños}

El cuadro 7 proporciona lo esencial de la información cifrada de la base DesInventar en materia de daños a las personas (muertos, heridos, damnificados,

18 La Paz/El Alto: 1950: 267000 habs.; 1976: 635 250; 1992: 1121 400; 2001: 1443 200; 2008 (proyección) 1736700.

Lima/Callao: 1961: 1902000 hab.; 1972: 3418 500; 1981: 4835 800; 1993: 6346 000; 2007: 8473000 .

Quito (distrito): 1950: 300000 hab.; 1974: 750 000; 1990: 1350 000; 2001: 1892 000; 2010: (proyección): 2384000. 
etc.) y de viviendas (destruidas o afectadas)19 desde 1970. La información no está completa y, en numerosos casos, la base de datos se limita a señalar la existencia de daños sin cifrarlos. Es así como 116 eventos de origen natural (o sea 21,4 \% de los eventos de este tipo) han afectado a cierto número de personas en Lima, sin que se pueda saber cuántas. También es el caso de 142 eventos en Quito (52,2 \% de los eventos de este tipo) y de 296 eventos en La Paz (94,5 \%). Las cifras de daños desembocan entonces en informaciones subevaluadas, la importancia de la subevaluación varía según la ciudad y según el daño considerado (personas afectadas, viviendas, costos, etc.). En consecuencia, es difícil proceder a un análisis de los daños en las diferentes ciudades y aún menos compararlas. La lectura del cuadro 7 permite sin embargo sacar algunas conclusiones:

- El número de decesos es relativamente poco elevado desde 1970: menos de 2500 muertos en el conjunto de las tres aglomeraciones, o sea 66 muertos por año aproximadamente. Las cifras denotan así la ausencia de un evento mayor durante el periodo en referencia. En Lima, el evento con mayores víctimas, y de lejos, fue el incendio del centro comercial Mesa Redonda en 2001 con 290 muertos. En Quito, el mayor número de víctimas mortales (entre 50 y 80) está ligado a tres accidentes de avión y de bus. En La Paz un fenómeno de origen natural mató al mayor número de personas (69 muertos durante las inundaciones del 19 de febrero de 2002)20.

- El número de personas damnificadas y afectadas es elevado en Lima, principalmente por eventos hidromorfológicos y por rupturas de la red de agua que ocasionan inundaciones y corte del servicio para las familias. Este número es menos elevado en las otras ciudades, lo que se explica en parte por la escasa proporción de eventos informados. En su conjunto, el número de viviendas destruidas o afectadas es también relativamente modesto (17 741 en Lima, 1902 en Quito y 1232 en La Paz). Esto refleja la subevaluación de la base DesInventar y la ausencia de un gran desastre como el sismo de Pisco del 15 de agosto 200721. Aunque incompletas, las cifras presentadas traducen la ocurrencia de un gran número de accidentes de pequeño o mediano impacto que afectan, en total, a una población importante.

- El inventario de los eventos recientes (1970-2007) es insuficiente para pronosticar los eventos de gran impacto que las tres ciudades podrían conocer; por ejemplo Quito frente a una erupción pliniana del Guagua Pichincha similar a la de 1660

19 La base de datos no permite analizar los costos de los daños pues casi ningún evento tienen esta información.

20 En cuanto a fenómenos de origen natural, un deslizamiento de tierra sobre la vía Baeza-Papallacta, en la margen del distrito, provocó el mayor número de víctimas (38) en Quito el 13 de junio de 2001. En Lima, el sismo de 1974 mató a 23 personas según la base DesInventar.

21 Según la evaluación INDECI del 29 de octubre de 2007, este sismo destruyó por si solo 47225 viviendas, hizo inhabitables 44927 y dañó de manera más ligera 47 225, principalmente en los departamentos de Ica y de Lima. 
Robert D’Ercole, Sébastien Hardy, Jérémy Robert
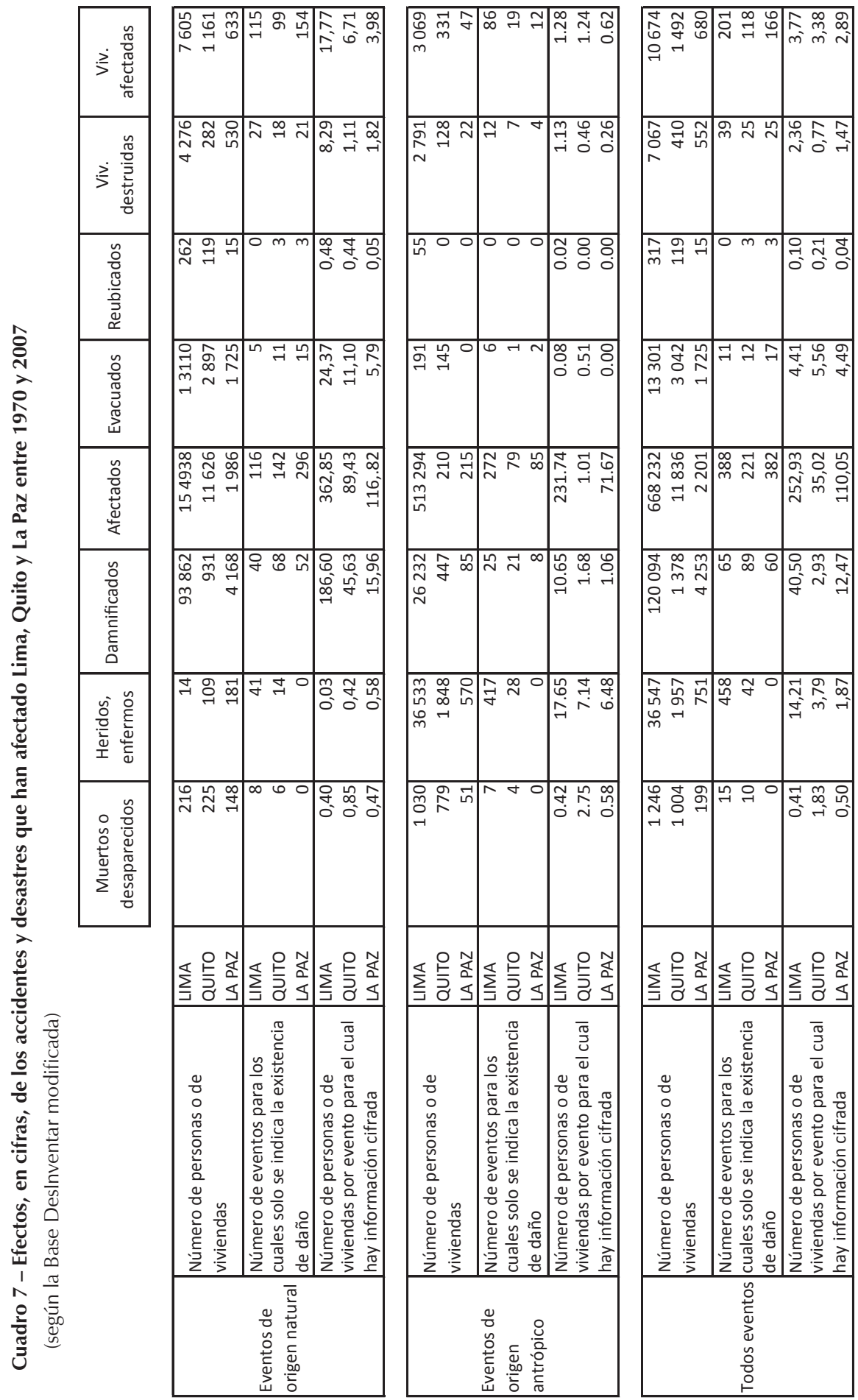
o en el caso de una erupción del volcán Cotopaxi cuyos lahares22 destruyeron una parte del actual territorio metropolitano en 1877. Un gran sismo, como los de 1755, 1797, 1859 y 1868, engendraría daños muy importantes en Quito. Peor aún, un sismo acompañado de un tsunami, como el que asoló Lima y El Callao en 1746 (más de 3000 muertos sobre 64000 habitantes) produciría daños considerables en la capital peruana, tanto en el aspecto humano como material, habida cuenta la mala calidad y la antigüedad de una parte importante del parque inmobiliario y de la ausencia de una política de prevención y de preparación ante el riesgo sísmico. En La Paz, eventos de tan gran magnitud parecen poco probables y ningún registro histórico hace mención de ellos. En cambio, son característicos de la capital boliviana los numerosos eventos de pequeña y mediana magnitud que acumulan sus efectos y penalizan su desarrollo económico y social.

- Las diferencias entre ciudades en materia de daños (cuadro 7), reflejan en gran parte las diferencias anteriormente observadas en lo que respecta al número de eventos. Por ende, globalmente los daños son mucho más elevados en Lima que en las dos otras capitales. El cálculo de los daños por evento permite relativizar estas diferencias, pero aun asi, los daños siguen siendo en su conjunto más elevados en Lima. Esto podría significar una mayor vulnerabilidad de esta ciudad, por lo menos en lo que se refiere a la cantidad de personas expuestas.

Más allá de las distinciones entre las tres ciudades, los daños por evento presentan diferencias según el tipo de evento. En las tres ciudades estos subrayan, el carácter brutal y más puntual de los accidentes y desastres de origen antrópico (más muertos y más heridos por evento). En cambio, los accidentes y desastres de origen natural resultan claramente más penalizadores si se considera el número de personas damnificadas o de viviendas destruidas o afectadas por evento. En Quito, por ejemplo, mientras el número de muertos por evento de origen antrópico es de 2,75 (contra 0,85 en fenómenos de origen natural), el número de viviendas afectadas por fenómenos de origen natural es de 6,7 (contra 1,2 en eventos de origen antrópico). Similares tendencias se encuentran en las dos otras ciudades.

\section{5. Diferenciaciones espaciales}

La cartografía de los eventos que han provocado daños y los análisis espaciales que esta permite, constituyen excelentes herramientas de identificación de los lugares vulnerables en donde pueden reproducirse daños similares en el futuro. El valor de esta cartografía se basa en la calidad de la base de datos que registra los eventos. Ahora bien, la información sobre la localización de los accidentes y desastres es de calidad muy variable en la base DesInventar. En algunos casos, los eventos están precisamente localizados lo que permite identificar hasta el edificio concernido. En otros, se indica una entidad espacial imprecisa como la inundación

22 Avalancha de lodo y escombros ligada a la fusión de una parte del glaciar que recubre el volcán. 
del 27 de diciembre de 1995 en La Paz que supestamente afectó a toda la ciudad, lo cual es imposible dada la topografía del territorio. Por ende, es irrealizable un tratamiento sistemático de las localizaciones de eventos, lo que constituye un defecto mayor de la base de datos.

La cartografía de los accidentes y desastres, aunque incompleta, es sin embargo posible y el caso de Lima tiene que distinguirse de los de Quito y La Paz. En Lima, en la mayoría de los casos, la información está dada por distritos. Solamente $8 \%$ de los eventos no han sido asociados a los 43 distritos de Lima o a los 6 distritos de El Callao. En consecuencia, ha sido posible realizar mapas estadísticos de eventos por distrito. Esta operación resultó imposible en Quito y La Paz en donde la información sobre las entidades administrativas es inutilizable23. Por ello, se ha intentado una cartografía de diferente tipo en La Paz, utilizando las informaciones de localización disponibles. El ejercicio no ha sido realizado en Quito donde la imprecisión en materia de localización es demasiado importante24.

\section{5. 1. Distribución espacial de los accidentes y desastres en Lima/Callao}

Las figuras 6 y 7 establecen la distinción entre eventos de origen natural y eventos antrópicos cuya distribución territorial es sensiblemente diferente.

En el caso de los accidentes y desastres de origen natural (figura 6), se observa una primera banda central este/oeste, a lo largo del río Rímac, desde los distritos de Lurigancho-Chosica y de Chaclacayo, hasta El Callao pasando por el Cercado de Lima, centro de la aglomeración. Están representados aquí eventos esencialmente ligados a fenómenos hidromorfológicos, sobre todo flujos de lodo (huaycos), deslizamientos de tierra río arriba e inundaciones río abajo. Un segundo anillo concierne a los distritos periféricos que ocupan las estribaciones de los Andes. Allí también predominan los eventos de tipo hidromorfológico, aunque su número es menos importante que en el caso precedente. La tercera banda es costera, va principalmente de Chorrillos a La Punta (provincia de El Callao), y es afectada principalmente por las marejadas y las densas neblinas.

La distribución de los accidentes y desastres de origen antrópico es muy diferente (figura 7), pues estos se concentran en los distritos centrales (principalmente el Cercado de Lima, El Callao, La Victoria, Rímac y San Martín de Porres, registrando cada uno más de 100 eventos desde 1970). El número de eventos se reduce a medida que uno se aleja de la zona central, ya sea hacia el este en dirección de los Andes, o hacia el oeste, de Barranco a San Miguel, en donde se encuentran algunos de los distritos más acomodados de la capital. Esta disposición se explica

23 En Quito, por ejemplo, solamente se establece una somera distinción entre el cantón Quito (o Distrito Metropolitano de Quito), que cubre la casi totalidad del espacio metropolitano y que agrupa la mayor parte de la población, y el pequeño cantón de Rumiñahui.

24 Para el caso de Quito, el lector podrá encontrar mayor información en el capítulo 3 de la obra de D'Ercole y Metzger (D'Ercole \& Metzger, 2004). Se han realizado varios mapas de localización de eventos que han ocasionado daños (inundaciones, movimientos en masa, aluviones) a partir de bases de datos específicas (particularmente la base de datos de Pierre Peltre, del IRD, que cubre el periodo 1900-1988). 


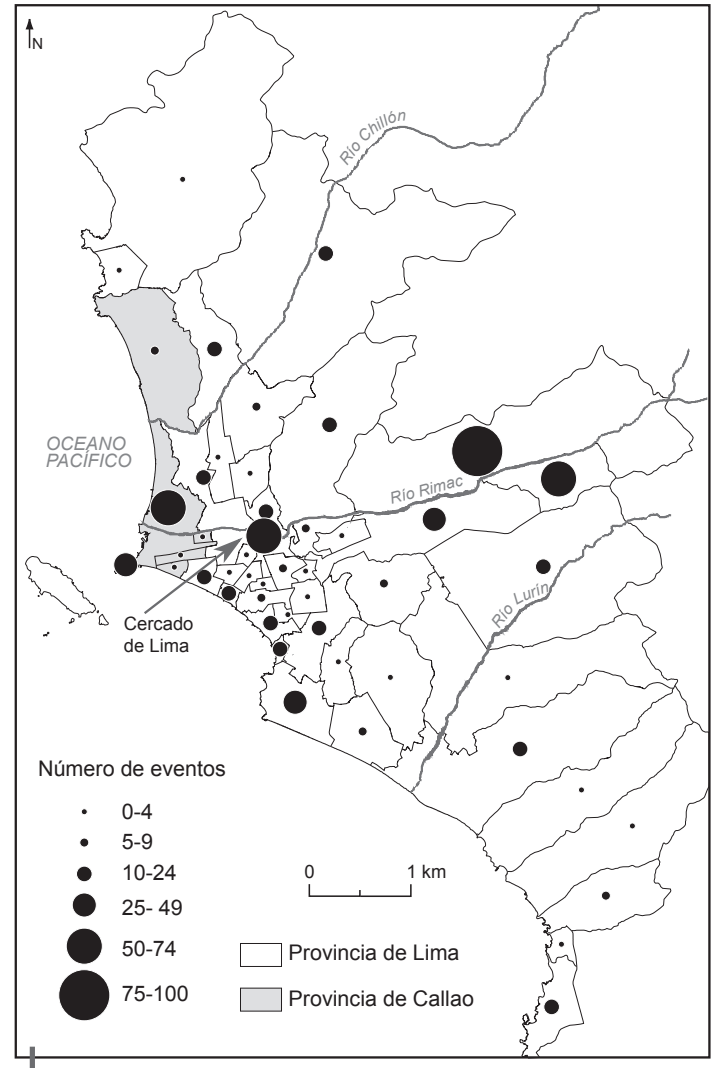

Figura 6 - Accidentes y desastres de origen natural ocurridos en Lima y Callao (1970-2006)

Fuente: Base DesInventar modificada

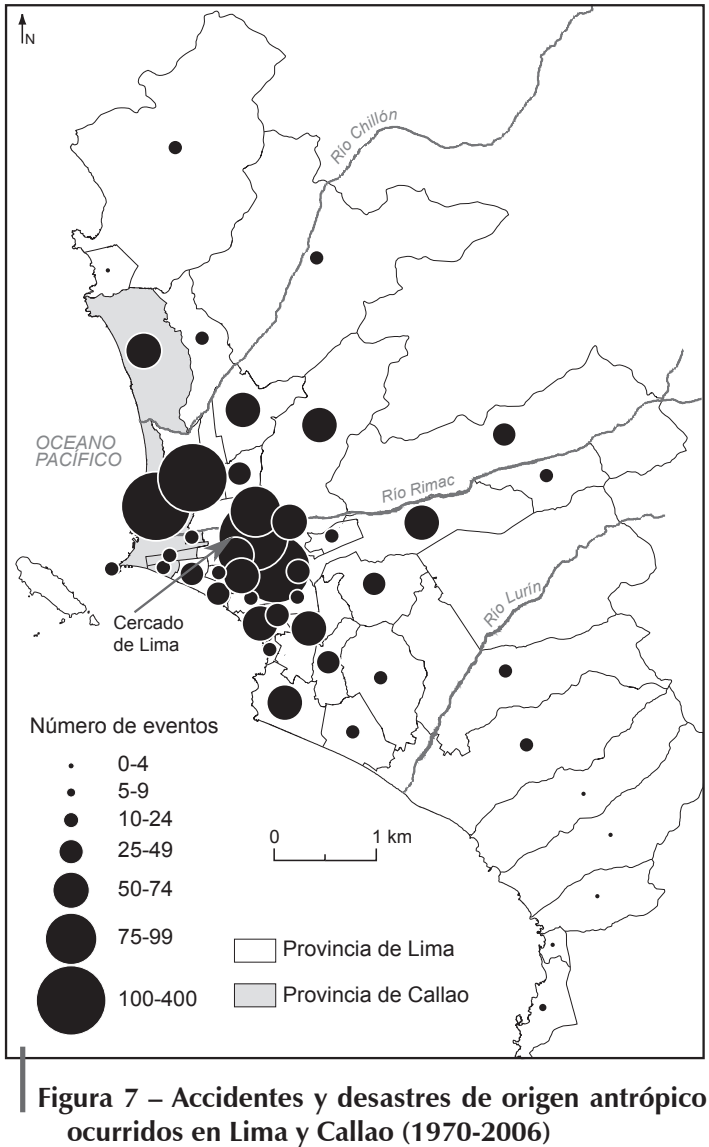

Fuente: Base DesInventar modificada

en parte por accidentes tecnológicos que se concentran en las cuatro principales zonas industriales de Lima (figura 8): en el distrito del Cercado, a lo largo del eje Lima-Callao; al norte, a lo largo de la costa del Pacífico en el distrito de El Callao y al borde de la Panamericana Norte en los distritos de Comas y San Martín de Porres; y por último, al este, en la zona industrial de Ate, a lo largo de la carretera Central.

La concentracion de eventos en la zona central de la ciudad se explica sobre todo por la alta densidad de población y por las precarias condiciones de vida de una parte importante de la misma en los distritos concernidos. Esto se traduce primero en condiciones propicias a la activación de incendios domésticos pero también en los locales comerciales o en los centros de almacenaje de materiales, siendo estos últimos ampliamente más numerosos en la zona central y en las proximidades de las zonas industriales. Además, la antigüedad de algunos barrios origina directamente cierto número de eventos, por ejemplo daños a los edificios o rupturas de canalizaciones de agua y desagüe. Por último, las contaminaciones parecen concentrarse allí, no solo a causa del estado obsoleto de las redes de 


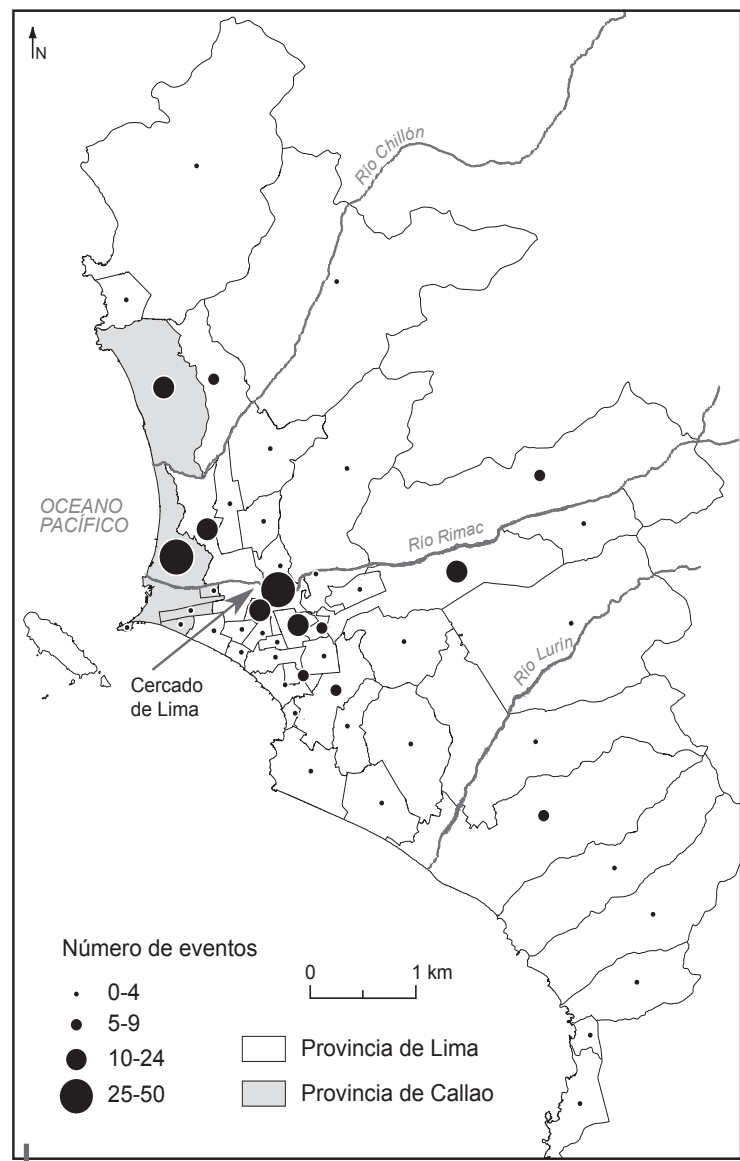

Figura 8 - Accidentes y desastres de tipo tecnológico ocurridos en Lima y Callao (1970-2006)

Fuente: Base DesInventar modificada

saneamiento sino también por los depósitos ilegales de basura y la falta de respeto de las reglas sanitarias, lo que está ligado en particular al comercio informal (mercados, reciclaje, etc.).

Existe una especificidad ligada a los tres ríos dado que no solo originan inundaciones sino también poluciones. Respecto a estas últimas, los eventos inventariados en la base de datos no han podido ser cartografiados sino rara vez, porque, en la mayoría de los casos, las contaminaciones conciernen al conjunto del (o de los) río (s), incluso las playas. Se observará sin embargo que la mayoría de los eventos están asociados al río Rímac, lo que puede explicarse en parte por la importancia de la urbanización de sus riberas, a diferencia de los ríos Lurín y Chillón, que atraviesan zonas mayoritariamente rurales. 


\section{5. 2. Distribución espacial de los accidentes y desastres en La Paz}

Tal como se ha dicho anteriormente, las informaciones disponibles sobre la aglomeración de La Paz no permiten, como en Lima, una cartografía estadística por entidad administrativa. Por consiguiente, se ha intentado una cartografía a partir de los datos de localización existentes, muy variables en calidad y en precisión. Dadas estas condiciones, no han podido ser cartografiados todos los accidentes y desastres que figuran en la base de datos. De 401 eventos, solo han podido ser cartografiados 236, es decir el $59 \%$ del total (57\% de los eventos de origen natural y $65 \%$ de los eventos antrópicos). Además, el mapa obtenido debe ser leído con precaución por las imprecisiones ya señaladas.

Los eventos puntuales bien localizados están representados mediante símbolos (círculos), por ejemplo el incendio de un edificio dado en una calle determinada. En cambio, las zonas pueden representar dos tipos de espacios, más o menos extensos: espacios realmente afectados por una inundación o una polución por ejemplo, y otros cuyo dibujo aproximativo está ligado a la imprecisión de la información inicial. Los eventos se refieren a veces a un barrio, incluso un distrito mientras que el conjunto de estos territorios no ha sido afectado en rigor. En los casos en que se carecía de mayor precisión, se ha tenido que representar en el mapa al conjunto del barrio o del distrito. La selección de la escala de representación desempeña igualmente un rol importante. Así, algunos eventos no han podido ser cartografiados porque se produjeron a una distancia bastante grande de la aglomeración, aun cuando estos la afectaron directamente. Es el caso, por ejemplo, de un deslizamiento de tierra en 1986 que se produjo en la zona rural de Hampaturi, situada a 17 kilómetros al nordeste de La Paz y que provocó dificultades de abastecimiento de agua en una gran parte de la aglomeración. Teniendo en cuenta estas reservas metodológicas, el mapa (figura 9) que asocia los eventos de origen natural y los eventos antrópicos, distinguiéndolos al mismo tiempo mediante colores diferentes, permite resaltar los espacios vulnerables a partir de los daños ocurridos en el pasado y el carácter recurrente de los eventos.

El análisis de la distribución de los accidentes y desastres cartografiados revela que estos han sido mucho más numerosos en el territorio de La Paz que en el de El Alto, y que sobre todo en La Paz, puede ser observado el daño recurrente de algunos espacios. Se trata principalmente de tres conjuntos: el centro de La Paz y su prolongación meridional; las vertientes este y las vertientes oeste del valle de La Paz. El valle del Choqueyapu, en el cual se ha efectuado la urbanización de La Paz, se caracteriza por muy fuertes declives sobre suelos blandos y poco resistentes a la erosión provocada por los numerosos torrentes que los recorren. Durante la estación de lluvias (diciembre-marzo), los deslizamientos de tierra se inician bastante fácilmente sobre las vertientes oeste y este del valle de La Paz. En cuanto al chorreo de las aguas pluviales, este se concentra rápidamente en el talweg y provoca inundaciones aguas abajo.

La distribución de los accidentes y desastres según su origen refuerza las diferencias observadas entre La Paz y El Alto. En El Alto, estos son esencialmente de origen 


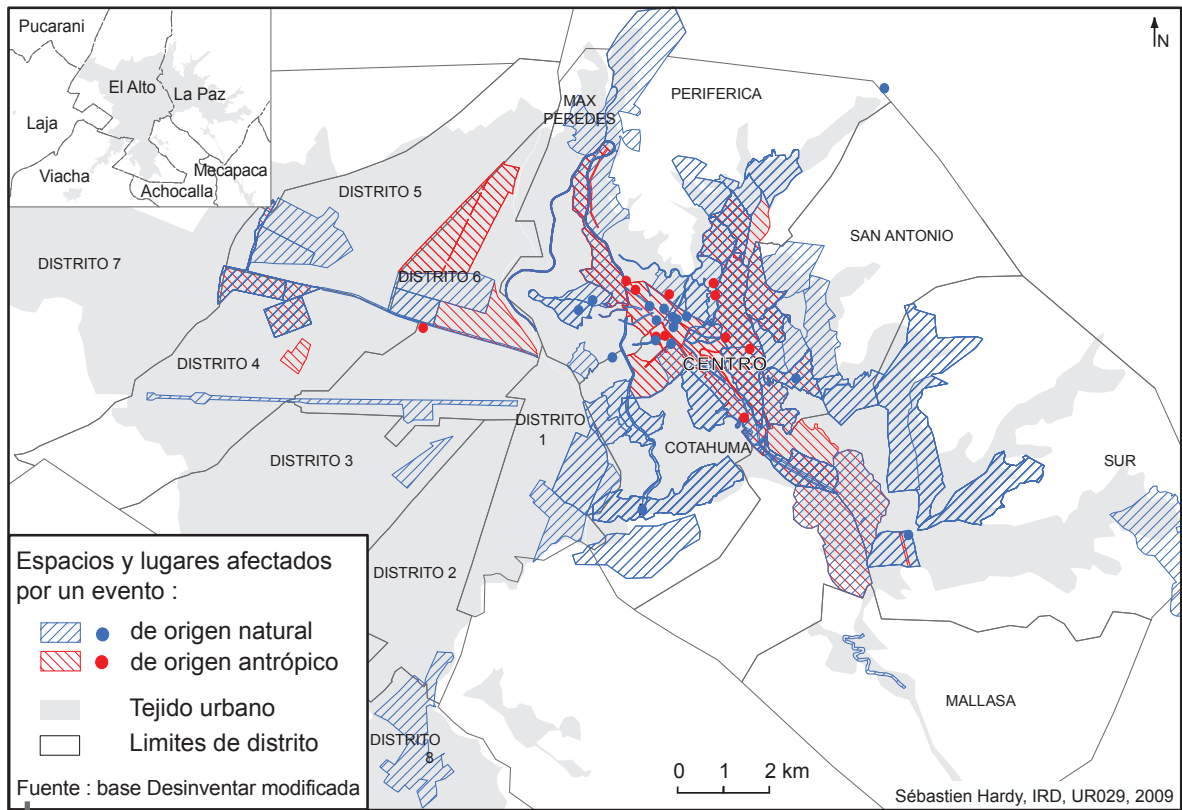

Figura 9 - Accidentes y desastres ocurridos en la aglomeración urbana de La Paz (1970-2007)

Fuente: Base DesInventar modificada

natural. Solo el distrito 6 se distingue por una alta concentración de eventos de origen antrópico, lo que parece estar ligado a la alta densidad del tejido urbano resultado de una urbanización más antigua (Sandoval \& Sostres, 1989), pero también de la yuxtaposición de variadas actividades ejercidas con muy poca seguridad 25 y de la proximidad de viviendas. Del lado paceño, mientras los eventos de origen natural están bien distribuidos sobre el conjunto del territorio, los de origen antrópico han afectado principalmente el espacio central y su prolongación meridional.

Además de las condiciones específicas de exposición a fenómenos dañinos, las diferencias observadas entre las dos municipalidades se explican en primer lugar por una diferencia de antigüedad. El tejido urbano de La Paz es más antiguo que el de El Alto. En 1970, año de la catalogación de la base, El Alto no había iniciado todavía su urbanización, la cual se aceleró recién a partir de los años 1980. Por otro lado, las fuentes utilizadas por DesInventar tienden a favorecer a La Paz en detrimento de El Alto. En efecto, los diarios consultados para construir los datos de DesInventar son de alcance nacional. Estos prestan escasa atención a El Alto, en beneficio de la municipalidad, sede de los órganos legislativos y ejecutivos de Bolivia26.

25 El distrito 6 acoge particularmente la feria bisemanal 16 de Julio, la mayor de Bolivia.

${ }^{26}$ La situación es diferente con El Alteño, el diario local de El Alto, pero este último no aparece como fuente de DesInventar (Hardy, 2008). 
Este interés selectivo de la prensa, fuente de DesInventar, con respecto al territorio, se encuentra igualmente en Quito y en Lima. En esta última ciudad, el gran número de eventos reportados en el caso del distrito central, el Cercado de Lima27, no se explica solamente por una exposición superior a las amenazas en relación con otros distritos, sino también por el mayor interés que prestan los medios de comunicación a este espacio histórico que alberga zonas de pobreza pero además a las sedes de la municipalidad y del gobierno nacional. El usuario de la base DesInventar y de los mapas producidos con esta base, como los aquí presentados, debe ser consciente de este sesgo y tomarlo en cuenta en sus conclusiones.

\section{CONCLUSIONES}

Hemos tratado de brindar una comparación entre las aglomeraciones de Lima, La Paz y Quito. Las tres, habida cuenta de la población total respectiva, han sido afectadas por un gran número de accidentes y desastres pero presentan tres perfiles diferentes en lo que se refiere al tipo de evento.

Lima presenta el rostro de una gran ciudad costera en la cual los eventos antrópicos descuellan, aun cuando el lugar ocupado por los eventos de origen natural es importante y no deja de ser inquietante para el futuro (caso de los sismos). Lima es uno de los principales polos industriales, a escala andina, lo que explica algunos accidentes, pero la mayoría de ellos es fruto de una vulnerabilidad que tiene sus raíces en las modalidades del desarrollo urbano (crecimiento muy rápido, ausencia de planificación urbana, importancia de la pobreza y de la informalidad, etc.).

Por lo contrario, La Paz es una ciudad de gran altitud en la cual los eventos son de origen natural, en su mayoría de pequeña y mediana magnitud y principalmente de caracter hidromorfológicos. Por ende, las preocupaciones están todavía muy focalizadas en los riesgos de origen natural aun cuando los fenómenos de origen antrópico son cada vez más evidentes. Sin embargo, las poblaciones no los toman en cuenta todavía y los medios de comunicación los obvian a menudo. Además, la dicotomía entre las municipalidades de La Paz y de El Alto, marcada en numerosos aspectos (históricos, económicos, sociales, etc.), no facilita la construcción de una visión de conjunto de los riesgos y de sus efectos sobre un territorio urbano sin embargo común.

Quito se presenta como una ciudad intermedia, más equilibrada en lo que se refiere a la relación entre los eventos de origen natural y los eventos antrópicos. Se acerca más a La Paz por ser una ciudad de altura en donde los procesos hidromorfológicos son muy activos, pero más cerca de Lima en algunos tipos de fenómenos (sismos), por un carácter industrial que tiende a afirmarse y por la posibilidad de conocer eventos de gran magnitud en el futuro.

27487 eventos (44 de origen natural y 443 de origen antrópico), es decir $16 \%$ del conjunto de los eventos. 
En el contexto mundial actual, en comparación con los grandes desastres recientes que han causado miles de víctimas y que han sido ampliamente mediatizados, las tres ciudades estudiadas aparecen como relativamente salvaguardadas. No por ello dejan de estar expuestas a grandes desastres, en particular Lima y Quito. La multitud de eventos relativamente menores registrados en el transcurso de las cuatro últimas décadas traduce sin embargo la existencia de una vulnerabilidad elevada que se expresará con fuerza el día en que se produzca un fenómeno de gran magnitud.

El análisis ha igualmente destacado la insuficiencia de las bases de datos actuales para conservar la memoria de los eventos pasados y caracterizarlos, sino también para proceder a una serie de análisis espacio temporales que permitan localizar los espacios más vulnerables y medir la evolución de esta vulnerabilidad. El artículo, en gran parte metodológico, ha mostrado el esfuerzo necesario del investigador para adaptarse a los datos existentes y adecuar estos últimos a los objetivos de investigación para sacar el mejor partido. También se ha mostrado que las modalidades de constitución de los datos no son jamás objetivas. Algunos fenómenos son privilegiados en una ciudad pero no en otra y los lugares son objeto de un interés selectivo que tiende generalmente a favorecer a los más reconocidos en el plano político y económico, en menosprecio de aquellos más desfavorecidos, cuya vulnerabilidad es seguramente más importante que lo es sugerido por las cifras. Estas insuficiencias o problemas constituyen obstáculos innegables para la comprensión de la vulnerabilidad y de los riesgos y, a fin de cuentas, para su reducción. Por consiguiente, es esencial mejorar el sistema de adquisición y de restitución de los conocimientos en materia de eventos pasados.

Por último, el análisis ha puesto en evidencia la complejidad del estudio de los accidentes y desastres en el medio urbano, la misma que está ligada a la fuerte antropización y a la complejidad de este tipo de medio (alta densidad de población, de actividades, multiplicación de las redes técnicas urbanas, etc.). Por lo tanto, resulta difícil distinguir los fenómenos de origen natural de los fenómenos antrópicos en función de un encadenamiento complejo de efectos, típico de los medios urbanos. Si bien los orígenes son a veces naturales, los efectos son siempre antrópicos. En consecuencia, los fenómenos son difíciles de clasificar, lo que explica en parte las imperfecciones de las bases de datos y el necesario esfuerzo del investigador para desembocar en interpretaciones que sean lo más exactas posibles. 


\section{Referencias citadas}

COLEMAN, F., 2006 - Frequency of Man-Made Disasters in the 20th Century. Journal of Contingencies and Crisis Management, vol. 14, n. ${ }^{\circ}$ 1: 3-11.

DAVILA, A., 1992 - Estabilidad geomorfológica de la región de Quito - Lámina 04. In: Atlas Infográfico de Quito. Socio-dinámica del espacio y política urbana: 41 láminas bilingües (español, francés), cuadros, gráficos, 29,7 x 42 cm; Quito, París: IGMIPGH ORSTOM.

D'ERCOLE, R. \& METZGER, P., 2004 - Vulnerabilidad del Distrito Metropolitano de Quito, 496 pp.; Quito, Ecuador: MDMQ-IRD. Colección Quito Metropolitano.

DUBOIS-MAURY, J. \& CHALINE, C., 2002 - Les risques urbains, 208 pp.; París: Armand

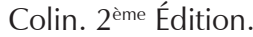

GUNDEL, S., 2005 - Towards a new Typology of Crises. Journal of Contigencies and Crisis Management, vol. 13, n. ${ }^{\circ}$ 3: 106-115.

HARDY, S., 2008 - Estudio de identificación de zonas de riesgos en los distritos 5 y 6 de la ciudad de El Alto, 66 pp.; La Paz: ECHO-COOPI.

LA RED-Corporación OSSO, 2004 - Guía del usuario, 40 pp.; DesInventar, DesConsultar 6.3.

MML, 2005 - Estrategia de Desarrollo Integral y reducción de la pobreza en Lima Metropolitana, 213 pp.; Lima: Municipalidad Metropolitana de Lima, Banco Mundial. Proyecto «Construyamos Futuro» de la Municipalidad Metropolitana de Lima y del Banco Mundial.

PIGEON, P., 2005 - Géographie critique des risques, 218 pp. ; París: Anthropos. Colección Economica.

SANDOVAL, G. \& SOSTRES, F., 1989 - La ciudad prometida; La Paz: SYSTEMA-ILDIS.

SIERRA, A., 2000 - Gestion des enjeux des espaces urbains à risque d'origine naturelle. Les versants et les quebradas de Quito, Équateur. Thèse de doctorat, Centre de Recherche en Analyses Géopolitiques, Université de Paris VIII, Vincennes-SaintDenis, 326 pp.

\section{Base de datos}

DESINVENTAR: http://online.desinventar.org/

EM-DAT: http://www.emdat.be/ 
